\title{
Synthesis and Antifungal Activity of $\beta$-Hydroxysulfides of 1,3-Dioxepane Series
}

\author{
Roman S. Pavelyev ${ }^{D},{ }^{1}$ Rusalia M. Vafina, ${ }^{1}$ Konstantin V. Balakin ${ }^{1 D},{ }^{1,2}$ Oleg I. Gnezdilov, ${ }^{3}$ \\ Aleksey B. Dobrynin, ${ }^{4}$ Olga A. Lodochnikova ${ }^{(1)},{ }^{4}$ Rashid Z. Musin, ${ }^{4}$ Galina A. Chmutova, ${ }^{1}$ \\ Svetlana A. Lisovskaya $\mathbb{D}^{5},{ }^{5}$ and Liliya E. Nikitina ${ }^{6}$ \\ ${ }^{1}$ Kazan (Volga Region) Federal University, Kremlyovskaya 18, Kazan 420008, Russia \\ ${ }^{2}$ I.M. Sechenov First Moscow State Medical University, Trubetskaya 8, Bldg 2, Moscow 119991, Russia \\ ${ }^{3}$ Kazan E. K. Zavoisky Physical-Technical Institute of the Russian Academy of Sciences, Sibirsky Tract, 10/7, Kazan \\ 420029, Russia \\ ${ }^{4}$ A.E. Arbuzov Institute of Organic and Physical Chemistry; KazSC, Russian Academy of Sciences, Arbuzova 8, Kazan \\ 420088, Russia \\ ${ }^{5}$ Kazan Scientific and Research Institute of Epidemiology and Microbiology, Bolshaya Krasnaya 67, Kazan 420015, Russia \\ ${ }^{6}$ Kazan State Medical University, Butlerova 49, Kazan 420012, Russia
}

Correspondence should be addressed to Roman S. Pavelyev; rpavelyev@gmail.com

Received 6 March 2018; Revised 11 July 2018; Accepted 25 July 2018; Published 10 October 2018

Academic Editor: Maria F. Carvalho

Copyright (c) 2018 Roman S. Pavelyev et al. This is an open access article distributed under the Creative Commons Attribution License, which permits unrestricted use, distribution, and reproduction in any medium, provided the original work is properly cited.

Synthesis of $\beta$-hydroxysulfides of 1,3-dioxepane series and their further functionalization were performed. Chiral $\beta$-hydroxysulfides were separated into enantiomers using enzymatic acylation by lipase PS. Study of antifungal activity of the obtained compounds showed that some enantiomerically pure 6-arylthio-1,3-dioxepan-5-ols represent promising antifungal drug candidates.

\section{Introduction}

$\beta$-Hydroxysulfides are attractive tools in organic synthesis, which are actively used in the synthesis of allylic alcohols, cyclic sulfides, thioketones, and physiologically active compounds [1-5]. Products of their oxidation, $\beta$-hydroxysulfones, are useful reagents for preparation of lactones [6], 2,5disubstituted tetrahydrofuranes [7], and vinyl sulfones [8]. Compounds containing phenylsulfonyl fragment are also widely used in organic synthesis [9].

Various 5- and 6-substituted 1,3-dioxepanes are relatively scarce chemotype in medicinal chemistry due to synthetic difficulties and stability issues under physiological conditions. Nevertheless, in several reports, they were described as promising physiologically active compounds. Thus, a series of 5-hydroxy-6-sulfonamido-1,3-dioxepanes were reported as hypoglycemic agents which were active in mice with diabetes [10]. The same group of researchers reported several $N$-sulfonyl-tetrahydro[ $[1,3]$ dioxepino $[5,6]$ azirines which also possessed hypoglycemic activity [11]. Optically active derivatives of 1,3-dioxepan-5-ol were described as flexible analogs of a known HIV-1 protease inhibitor (PI) darunavir [12]. They demonstrated excellent potency against a variety of multi-PI-resistant clinical strains, and the structure-activity studies indicated that the ring size, stereochemistry, and position of oxygens were important for the observed activity.

In attempt to combine the $\beta$-hydroxysulfide and 1,3 dioxepane structural motifs, we previously synthesized a series of 2-phenyl-6-arylthio-1,3-dioxepan-5-ols, which possessed a moderate antifungal activity [13]. In order to optimize structure-activity parameters of this interesting structural chemotype, in this work we have prepared a series of novel chiral $\beta$-hydroxysulfides of 1,3-dioxepane series and 
studied their antifungal activity against a panel of pathogenic microscopic fungi. It should be noted that microscopic fungi (micromycetes), causing mycoses, are significantly different from other infectious agents. Fungi are eukaryotic and are characterized by the presence of a rigid outer wall. Micromycetes are classified according to morphological characteristics, the degree of pathogenicity, and the ability to cause diseases of various organs and systems. In this work, we used four aggressive clinical isolates of Candida albicans, Aspergillus fumigatus, Epidermophyton floccosum, and Mucor pusillus species. Among mycelial pathogens of invasive mycoses, Aspergillus spp. are the most widespread. Dermatomycetes (Epidermophyton spp.) are one of the most common causative agents of superficial mycoses of skin, hair, and nails. Zygomycetes (Mucor spp.) cause extremely severe invasive mycoses with a very high mortality rate. And, finally, the vast majority of cases of fungal lesions of mucous membranes can be attributed to infections caused by yeast fungi of Candida species.

\section{Materials and Methods}

2.1. General Information. Chromatographic purification of compounds was carried out using column chromatography on Acros silica gel (60-200 mesh). Reaction progress and purity of compounds were monitored by TLC on Sorbfil PTLC-AF-A-UF plates.

Melting points of the products were determined using a Stanford Research Systems M.P.A-100 OptiMelt apparatus.

${ }^{1} \mathrm{H}$ and ${ }^{13} \mathrm{C}$ NMR spectra were recorded on a "Bruker AVANCE 400" at operating frequency 400 and $100 \mathrm{MHz}$, respectively, using TMS as an internal standard.

Gas chromatography/mass spectrometry experiments were performed using DFS “Thermo Electron Corporation” apparatus. The following experimental conditions for mass spectrometry measurements were used: method of ionization: electron ionization; electron energy: $70 \mathrm{eV}$; and ion source temperature: $280^{\circ} \mathrm{C}$. For gas chromatography analysis, a capillary column DB-5MS $(30 \times 0.25)$ was used with helium as the gas carrier. The following experimental conditions were applied: gas-carrier rate $1 \mathrm{ml} / \mathrm{min}$; injector temperature $250^{\circ} \mathrm{C}$; temperature gradient: $50{ }^{\circ} \mathrm{C}$ $(1 \mathrm{~min})-6 \mathrm{grad} / \mathrm{min}-120^{\circ} \mathrm{C}-20 \mathrm{grad} / \mathrm{min}-280^{\circ} \mathrm{C}(15 \mathrm{~min})$; and sample volume $0.3 \mu \mathrm{l}$.

HPLC experiment was performed using the Chiralpak AGP column $(15.0 \times 0.4 \mathrm{sm}, 5 \mu \mathrm{m})$. A solution of methanol and $0.01 \mathrm{M}$ ammonium acetate buffer $(1: 99 \mathrm{v} / \mathrm{v})$ was used as the eluent. The elution rate was $0.9 \mathrm{ml} / \mathrm{min}$, and the product was detected spectrophotometrically at $250 \mathrm{~nm}$.

MALDI-TOF experiments were performed using an ULTRAFLEX III TOF/TOF mass spectrometer (Bruker Daltonik GmbH, Germany). The spectra of positive ions were recorded in linear mode with ion acceleration up to $20 \mathrm{keV}$. The energy of the laser beam was attenuated down to $70 \%$ of the full laser power. Analyte and $p$-nitroaniline matrix compounds were dissolved in acetone $(1 \%$ in case of matrix and $0.1 \%$ in case of analyte) using glassware. The samples were prepared by a "dried-droplet" method: $0.3 \mu \mathrm{l}$ droplets of the solutions were deposited on the marked spots on the standard target plate "AnchorChip" (Bruker Daltonik $\mathrm{GmbH}$, Germany) and left to dry.

For analyzing optically active substances, "ADP 440" $(B+S)$ polarimeter was used.

Quantum-chemical calculations were performed by DFT method B3LYP/6-31G(d,p) using Gaussian-98 [14] program with full geometry optimization without restrictions on symmetry, and a matrix of second derivatives was calculated for all stationary points. All discussed structures have only positive frequencies. Scaling factors [15] were not introduced.

Compounds 2 [16], 11 [17], 12 [18], 13 [19], 14 [20], and 19 [28] were prepared according to previously described methods with insignificant modifications.

\subsection{Experimental Details}

2.2.1. 3,5,8-Trioxabicyclo[5.1.0]octane (2). Oxone (169 mmol) was slowly added by portions to a stirred solution of 1,3-dioxacyclohept-5-en $1(130.2 \mathrm{mmol})$ and $\mathrm{NaHCO}_{3}$ $(619 \mathrm{mmol})$ in $100 \mathrm{ml}$ of acetone-water mixture $(1: 1 \mathrm{v} / \mathrm{v})$ for 3 hours at $20^{\circ} \mathrm{C}$. Then, the reaction mixture was additionally stirred for 1 hour. The product was extracted with $\mathrm{CH}_{2} \mathrm{Cl}_{2}(2 \times 50 \mathrm{ml})$. Organic layers were combined and dried over $\mathrm{MgSO}_{4}$. The solvent was evaporated under reduced pressure, and the product was purified by column chromatography on silica gel (eluent petroleum ether-ethyl acetate, $7: 1$ ). Yield $75 \%$, colorless crystals, m.p. $56^{\circ} \mathrm{C}-57^{\circ} \mathrm{C}$.

2.2.2. 6-(Phenylthio)-1,3-dioxepan-5-ol (3). (1) General Procedure for Preparation of $\beta$-Hydroxysulfides 3, 21-23

A mixture of thiophenol $(2.7 \mathrm{mmol}), \mathrm{K}_{2} \mathrm{CO}_{3}$ $(0.15 \mathrm{mmol})$, and epoxide $(2.6 \mathrm{mmol})$ was heated until the appearance of the first bubbles. The heating source was removed, and a short-time $(<1$ minute) spontaneous boiling-up with a sharp increase of the temperature was observed. The reaction mixture was cooled, and the product was purified by column chromatography (eluent petroleum ether-ethyl acetate, $4: 1$ ).

Yield $93 \%$, colorless oil. ${ }^{1} \mathrm{H}$ NMR $\left(\mathrm{CDCl}_{3}\right), \delta: 3.13$ br. s (1H, OH), 3.23-3.27 m $\left(1 \mathrm{H}, \mathrm{H}^{6},{ }^{3} J\left(\mathrm{H}^{6} \mathrm{H}^{5}\right)=5.5 \mathrm{~Hz},{ }^{3} J\left(\mathrm{H}^{6}\right.\right.$ $\left.\left.\mathrm{H}_{\mathrm{A}}^{7}\right)=6.5 \mathrm{~Hz},{ }^{3} \mathrm{~J}\left(\mathrm{H}^{6} \mathrm{H}_{\mathrm{B}}^{7}\right)=2.7 \mathrm{~Hz}\right), 3.69-3.75 \mathrm{~m}\left(1 \mathrm{H}, \mathrm{H}^{5},{ }^{3} \mathrm{~J}\right.$ $\left.\left(\mathrm{H}^{5} \mathrm{H}^{4}{ }_{\mathrm{A}}\right)=6.0 \mathrm{~Hz},{ }^{3} J\left(\mathrm{H}^{5} \mathrm{H}_{\mathrm{B}}^{4}\right)=1.7 \mathrm{~Hz}\right), 3.75-3.79 \mathrm{~m}(1 \mathrm{H}$, $\left.\mathrm{H}_{\mathrm{A}}^{4},{ }^{2} J\left(\mathrm{H}_{\mathrm{A}}^{4} \mathrm{H}_{\mathrm{B}}^{4}\right)=-12.0 \mathrm{~Hz}\right), 3.81-3.88 \mathrm{~m}\left(1 \mathrm{H}_{,} \mathrm{H}_{\mathrm{A}}^{7},{ }^{2} J\right.$ $\left.\left(\mathrm{H}_{\mathrm{A}}^{7} \mathrm{H}_{\mathrm{B}}^{7}\right)=-12.5 \mathrm{~Hz}\right), 4.04-4.12 \mathrm{~m}\left(2 \mathrm{H}, \mathrm{H}_{\mathrm{B}}^{7}, \mathrm{H}_{\mathrm{B}}^{4}\right), 4.74$ and $4.77\left(\mathrm{AB}, 2 \mathrm{H}, 2 \mathrm{H}^{2},{ }^{2} J\left(\mathrm{H}_{\mathrm{A}}^{2} \mathrm{H}_{\mathrm{B}}^{2}\right)=-4.5 \mathrm{~Hz}\right), 7.24-$ $7.48 \mathrm{~m}\left(5 \mathrm{H}, \mathrm{C}_{6} \mathrm{H}_{5}\right) .{ }^{13} \mathrm{C} \mathrm{NMR}\left(\mathrm{CDCl}_{3}\right), \delta: 54.63\left(\mathrm{C}^{6}\right), 65.32$ $\left(\mathrm{C}^{7}\right), 66.39\left(\mathrm{C}^{4}\right), 71.34\left(\mathrm{C}^{5}\right), 94.07\left(\mathrm{C}^{2}\right), 127.32\left(\mathrm{C}_{\mathrm{Ar}}\right), 129.05$ $\left(\mathrm{C}_{\mathrm{Ar}}\right), 131.73\left(\mathrm{C}_{\mathrm{Ar}}\right), 133.22\left(\mathrm{C}_{\mathrm{Ar}}\right)$. MS $(\mathrm{EI}): m / z(\%)=226$ $\left(\mathrm{M}^{+}, 56\right)$.

2.2.3. 6-(Phenylsulfonyl)-1,3-dioxepan-5-ol (4). Oxone $(2.0 \mathrm{mmol})$ was added by portions for 1.5 hour to a stirred solution of sulfides $(1.5 \mathrm{mmol})$ and $\mathrm{NaHCO}_{3}(7.3 \mathrm{mmol})$ in $20 \mathrm{ml}$ of acetone-water mixture $(1: 1, \mathrm{v} / \mathrm{v})$. The reaction mixture was stirred for 1 hour, then $\mathrm{CHCl}_{3}(100 \mathrm{ml})$ was added. The aqueous layer was separated, saturated with 
$\mathrm{NaCl}$, and extracted with $\mathrm{CHCl}_{3}$. Organic phases were combined and dried over $\mathrm{MgSO}_{4}$. The product was purified by column chromatography (eluent petroleum ether-ethyl acetate, $2: 1)$.

Yield $85 \%$, colorless oil. ${ }^{1} \mathrm{H}$ NMR $\left(\mathrm{CDCl}_{3}\right), \delta: 3.24$ br. $s$ $(1 \mathrm{H}, \mathrm{OH}), 3.30-3.36 \mathrm{~m}\left(1 \mathrm{H}, \mathrm{H}^{6},{ }^{3} J\left(\mathrm{H}^{6} \mathrm{H}^{5}\right)=6.75 \mathrm{~Hz},{ }^{3} J\left(\mathrm{H}^{6}\right.\right.$ $\left.\left.\mathrm{H}^{7}{ }_{\mathrm{B}}\right)=3.65 \mathrm{~Hz},{ }^{3} J\left(\mathrm{H}^{6} \mathrm{H}_{\mathrm{A}}^{7}\right)=8.14 \mathrm{~Hz}\right), 3.73-3.80 \mathrm{~m}(1 \mathrm{H}$, $\left.\mathrm{H}_{\mathrm{A}}^{4},{ }^{2} J\left(\mathrm{H}_{\mathrm{A}}^{4} \quad \mathrm{H}_{\mathrm{B}}^{4}\right)=-12.23 \mathrm{~Hz},{ }^{3} J\left(\mathrm{H}_{\mathrm{A}}^{4} \mathrm{H}^{5}\right)=7.1 \mathrm{~Hz}\right)$, $3.81-3.88 \mathrm{~m}\left(1 \mathrm{H}, \mathrm{H}^{7}{ }_{\mathrm{A}},{ }^{2} J\left(\mathrm{H}^{7}{ }_{\mathrm{A}} \mathrm{H}^{7}{ }_{\mathrm{B}}\right)=-12.8 \mathrm{~Hz}\right), 3.96-$ $4.04 \mathrm{~m}\left(2 \mathrm{H}, \mathrm{H}_{\mathrm{B}}^{7}, \mathrm{H}^{4}{ }_{\mathrm{A}},{ }^{3} \mathrm{~J}\left(\mathrm{H}_{\mathrm{B}}^{4} \mathrm{H}^{5}\right)=3.3 \mathrm{~Hz}\right), 4.26 \mathrm{dt}(1 \mathrm{H}$, $\left.\mathrm{H}^{5},{ }^{3} \mathrm{~J}\left(\mathrm{H}^{5} \mathrm{OH}\right)=3.0 \mathrm{~Hz}\right), 4.60$ and $4.71\left(\mathrm{AB}, 2 \mathrm{H}, 2 \mathrm{H}^{2}\right.$, $\left.{ }^{2} J\left(\mathrm{H}_{\mathrm{B}}^{2} \mathrm{H}^{2} \mathrm{~A}\right)=-4.82 \mathrm{~Hz}\right), 7.57-7.94 \mathrm{~m}\left(5 \mathrm{H}, \mathrm{C}_{6} \mathrm{H}_{5}\right) .{ }^{13} \mathrm{C}$ $\operatorname{NMR}\left(\mathrm{CDCl}_{3}\right), \delta: 61.57\left(\mathrm{C}^{7}\right), 67.91\left(\mathrm{C}^{5}\right), 68.59\left(\mathrm{C}^{4}\right), 69.96$ $\left(\mathrm{C}^{6}\right), 95.07\left(\mathrm{C}^{2}\right), 128.72\left(\mathrm{C}_{\mathrm{Ar}}\right), 129.57\left(\mathrm{C}_{\mathrm{Ar}}\right), 134.51\left(\mathrm{C}_{\mathrm{Ar}}\right)$, $137.41\left(\mathrm{C}_{\mathrm{Ar}}\right)$. MALDI-MS: $259[\mathrm{M}+\mathrm{H}]^{+}, 281[\mathrm{M}+\mathrm{Na}]^{+}$, $297[\mathrm{M}+\mathrm{K}]^{+}$.

2.2.4. 6-(Phenylthio)-1,3-dioxepan-5-yl Acetate (5). $\mathrm{Ac}_{2} \mathrm{O}$ (7.5 mmol), $\mathrm{Et}_{3} \mathrm{~N}(7.5 \mathrm{mmol})$, and DMAP $(0.05 \mathrm{mmol})$ were successively added to a stirred solution of hydroxyl sulfide ( $5 \mathrm{mmol}$ ) in $20 \mathrm{ml}$ of $\mathrm{CH}_{2} \mathrm{Cl}_{2}$, and the reaction mixture was stirred for 1 hour. Then, the solvent was evaporated under reduced pressure, and the product was purified by column chromatography (eluent petroleum ether-ethyl acetate, $7: 1$ ).

Yield $96 \%$, colorless oil. ${ }^{1} \mathrm{H}$ NMR $\left(\mathrm{CDCl}_{3}\right), \delta: 2.02 \mathrm{~s}(3 \mathrm{H}$, $\left.\mathrm{CH}_{3}\right), 3.33 \mathrm{dt}\left(1 \mathrm{H}, \mathrm{H}^{6},{ }^{3} J\left(\mathrm{H}^{6} \mathrm{H}^{5}\right)=5.7 \mathrm{~Hz},{ }^{3} J\left(\mathrm{H}^{6} \mathrm{H}^{7}{ }_{\mathrm{A}}\right)=\right.$ $\left.6.35 \mathrm{~Hz},{ }^{3} J\left(\mathrm{H}^{6} \mathrm{H}_{\mathrm{B}}^{7}\right)=2.5 \mathrm{~Hz}\right), 3.78 \mathrm{dd}\left(1 \mathrm{H}, \mathrm{H}_{\mathrm{A}}^{7},{ }^{2} J\left(\mathrm{H}_{\mathrm{A}}^{7}\right.\right.$ $\left.\left.\mathrm{H}^{7}{ }_{\mathrm{B}}\right)=-12.3 \mathrm{~Hz}\right), 3.82 \mathrm{dd}\left(1 \mathrm{H}, \mathrm{H}^{4}{ }_{\mathrm{A}},{ }^{2} J\left(\mathrm{H}_{\mathrm{A}}^{4} \mathrm{H}_{\mathrm{B}}^{4}\right)=-12.6 \mathrm{~Hz}\right.$, $\left.{ }^{3} J\left(\mathrm{H}_{\mathrm{A}}^{4} \mathrm{H}^{5}\right)=5.5 \mathrm{~Hz}\right), 3.99 \mathrm{dd}\left(1 \mathrm{H}, \mathrm{H}_{\mathrm{B}}^{4},{ }^{3} J\left(\mathrm{H}^{4}{ }_{\mathrm{B}} \mathrm{H}^{5}\right)=2.4 \mathrm{~Hz}\right)$, $4.09 \mathrm{dd}\left(1 \mathrm{H}, \mathrm{H}_{\mathrm{B}}^{7}\right), 4.63$ and $4.75\left(\mathrm{AB}, 2 \mathrm{H}, 2 \mathrm{H}^{2},{ }^{2} J\left(\mathrm{H}^{2}{ }_{\mathrm{A}}\right.\right.$ $\left.\left.\mathrm{H}^{2}{ }_{\mathrm{B}}\right)=-4.5 \mathrm{~Hz}\right), 4.91 \mathrm{~m}\left(1 \mathrm{H}, \mathrm{H}^{5}\right), 7.18-7.47 \mathrm{~m}\left(5 \mathrm{H}, \mathrm{C}_{6} \mathrm{H}_{5}\right)$. ${ }^{13} \mathrm{C}$ NMR $\left(\mathrm{CDCl}_{3}\right), \delta: 20.53\left(\mathrm{CH}_{3}\right), 51.59\left(\mathrm{C}^{6}\right), 64.94\left(\mathrm{C}^{7(4)}\right)$, $65.01\left(\mathrm{C}^{4(7)}\right), 73.30\left(\mathrm{C}^{5}\right), 93.91\left(\mathrm{C}^{2}\right), 127.01\left(\mathrm{C}_{\mathrm{Ar}}\right), 128.69\left(\mathrm{C}_{\mathrm{Ar}}\right)$, $131.46\left(\mathrm{C}_{\mathrm{Ar}}\right), 133.07\left(\mathrm{C}_{\mathrm{Ar}}\right), 169.42(\mathrm{CO})$. MS (EI): $m / z(\%)=$ $268\left(\mathrm{M}^{+}, 5\right)$.

2.2.5. 6-(Phenylsulfonyl)-1,3-dioxepan-5-yl Acetate (6). Oxone $(2.0 \mathrm{mmol})$ was added by portions for 1.5 hour to a stirred solution of sulfides $(1.5 \mathrm{mmol})$ and $\mathrm{NaHCO}_{3}$ $(7.3 \mathrm{mmol})$ in $20 \mathrm{ml}$ of acetone-water mixture $(1: 1, \mathrm{v} / \mathrm{v})$. The reaction mixture was stirred for 1 hour, and then $\mathrm{CHCl}_{3}$ $(20 \mathrm{ml})$ was added. The aqueous layer was separated, saturated with $\mathrm{NaCl}$, and extracted with $\mathrm{CHCl}_{3}$. Organic layers were combined and dried over $\mathrm{MgSO}_{4}$. The product was purified by column chromatography (eluent petroleum ether-ethyl acetate, $7: 1$ ).

Yield $80 \%$, colorless crystals, m.p. $88^{\circ} \mathrm{C}-89^{\circ} \mathrm{C} .{ }^{1} \mathrm{H}$ NMR $\left(\mathrm{CDCl}_{3}\right), \delta: 1.84 \mathrm{~s}\left(3 \mathrm{H}, \mathrm{CH}_{3}\right), 3.48-3.53 \mathrm{~m}\left(1 \mathrm{H}, \mathrm{H}^{6},{ }^{3} J\left(\mathrm{H}^{6}\right.\right.$ $\left.\left.\mathrm{H}^{5}\right)=5.6 \mathrm{~Hz},{ }^{3} J\left(\mathrm{H}^{6} \mathrm{H}_{\mathrm{A}}{ }^{\mathrm{C}}\right)=6.88 \mathrm{~Hz},{ }^{3} J\left(\mathrm{H}^{6} \mathrm{H}^{7}{ }_{\mathrm{B}}\right)=3.03 \mathrm{~Hz}\right)$, $3.87-3.97 \mathrm{~m}\left(2 \mathrm{H}, \mathrm{H}_{\mathrm{A}}^{4}, \mathrm{H}_{\mathrm{B}}^{4},{ }^{2} J\left(\mathrm{H}^{4}{ }_{\mathrm{A}} \mathrm{H}^{4}{ }_{\mathrm{B}}\right)=-13.06 \mathrm{~Hz}\right.$, $\left.{ }^{3} J\left(\mathrm{H}^{4}{ }_{\mathrm{A}} \mathrm{H}^{5}\right)=4.9 \mathrm{~Hz},{ }^{3} J\left(\mathrm{H}_{\mathrm{B}}^{4} \mathrm{H}^{5}\right)=2.75 \mathrm{~Hz}\right), 4.13 \mathrm{dd}(1 \mathrm{H}$, $\left.\mathrm{H}_{\mathrm{A}}^{7},{ }^{2} J\left(\mathrm{H}_{\mathrm{A}}^{7} \mathrm{H}_{\mathrm{B}}^{7}\right)=-12.96 \mathrm{~Hz}\right), 4.36 \mathrm{dd}\left(1 \mathrm{H}, \mathrm{H}_{\mathrm{B}}^{7}\right), 4.63$ and $4.81\left(\mathrm{AB}, 2 \mathrm{H}, 2 \mathrm{H}^{2},{ }^{2} \mathrm{~J}\left(\mathrm{H}^{2} \mathrm{~A} \mathrm{H}_{\mathrm{B}}{ }_{\mathrm{B}}\right)=-5.16 \mathrm{~Hz}\right), 5.34 \mathrm{~m}(1 \mathrm{H}$, $\left.\mathrm{H}^{5}\right), 7.56-7.95 \mathrm{~m}\left(5 \mathrm{H}, \mathrm{C}_{6} \mathrm{H}_{5}\right) .{ }^{13} \mathrm{C} \mathrm{NMR}\left(\mathrm{CDCl}_{3}\right), \delta: 20.62$ $\left(\mathrm{CH}_{3}\right), 61.83\left(\mathrm{C}^{7}\right), 67.83\left(\mathrm{C}^{6}\right), 67.94\left(\mathrm{C}^{4}\right), 69.58\left(\mathrm{C}^{5}\right), 95.90$ $\left(\mathrm{C}^{2}\right), 128.84\left(\mathrm{C}_{\mathrm{Ar}}\right), 129.33\left(\mathrm{C}_{\mathrm{Ar}}\right), 134.18\left(\mathrm{C}_{\mathrm{Ar}}\right), 138.19\left(\mathrm{C}_{\mathrm{Ar}}\right)$, $169.42(\mathrm{CO})$. MALDI-MS: $301[\mathrm{M}+\mathrm{H}]^{+}, 323[\mathrm{M}+\mathrm{Na}]^{+}$, $339[\mathrm{M}+\mathrm{K}]^{+}$.
2.2.6. 5-(Phenylsulfonyl)-4,7-dihydro-1,3-dioxepine (7). $\mathrm{K}_{2} \mathrm{CO}_{3}(9 \mathrm{mmol})$ was added to a solution of acetate 5 ( $3 \mathrm{mmol}$ ) in $20 \mathrm{ml}$ of methanol. The mixture was stirred for 1 hour, $\mathrm{K}_{2} \mathrm{CO}_{3}$ was filtered off, and then the solvent was removed. The product was purified by column chromatography (eluent petroleum ether-ethyl acetate, 1:1).

Yield $95 \%$, colorless crystals, m.p. $86^{\circ} \mathrm{C}-87^{\circ} \mathrm{C} .{ }^{1} \mathrm{H}$ NMR $\left(\mathrm{CDCl}_{3}\right), \delta: 4.41-4.45$ br. $\mathrm{m}\left(2 \mathrm{H}, \mathrm{H}^{4}\right), 4.45-4.48$ br. $\mathrm{m}(2 \mathrm{H}$, $\left.\mathrm{H}^{7}\right), 4.82 \mathrm{~s}\left(2 \mathrm{H}, \mathrm{H}^{2}\right), 7.02 \mathrm{t}\left(1 \mathrm{H}, \mathrm{H}^{6},{ }^{3} J\left(\mathrm{H}^{6} \mathrm{H}^{7}\right)=3.3 \mathrm{~Hz}\right)$, 7.51-7.88 m $\left(5 \mathrm{H}, \mathrm{C}_{6} \mathrm{H}_{5}\right) \cdot{ }^{13} \mathrm{C}$ NMR $\left(\mathrm{CDCl}_{3}\right), \delta: 63.80\left(\mathrm{C}^{7}\right)$, $65.95\left(\mathrm{C}^{4}\right), 96.58\left(\mathrm{C}^{2}\right), 128.01\left(\mathrm{C}_{\mathrm{Ar}}\right), 129.54\left(\mathrm{C}_{\mathrm{Ar}}\right), 133.81$ $\left(\mathrm{C}_{\mathrm{Ar}}\right), 139.20\left(\mathrm{C}_{\mathrm{Ar}}\right), 141.35\left(\mathrm{C}^{6}\right), 143.52\left(\mathrm{C}^{5}\right)$. MALDI-MS: $241[\mathrm{M}+\mathrm{H}]^{+}$.

2.2.7. cis-2,3-Epoxybutane-1,4-diol (11). Compound 11 was obtained from compound $10(1.76 \mathrm{~g}, 20 \mathrm{mmol})$ using a procedure similar to that used for the synthesis of epoxide 2. Yield $85 \%(1.77 \mathrm{~g})$, colorless crystals, m.p. $50-51^{\circ} \mathrm{C}$.

2.2.8. 3-(Phenylthio)butane-1,2,4-triol (12). A mixture of epoxide $11(1.77 \mathrm{~g}, 17 \mathrm{mmol})$, thiophenol $(1.91 \mathrm{ml}$, $18.7 \mathrm{mmol})$, and DABCO $(0.019 \mathrm{~g}, 0.17 \mathrm{mmol})$ in $50 \mathrm{ml}$ of water was heated on an oil bath $\left(90^{\circ} \mathrm{C}\right)$ under stirring. The reaction was monitored by TLC. The reaction mixture was extracted with $\mathrm{CH}_{2} \mathrm{Cl}_{2}(3 \times 15 \mathrm{ml})$, and the organic layers were combined and dried over $\mathrm{MgSO}_{4}$. The product was purified by column chromatography (eluent acetone). Yield $82 \%$, colorless crystals, m.p. $91-92^{\circ} \mathrm{C}$.

2.2.9. (Z)-4-Hydroxybut-2-en-1-yl Acetate (13). A solution of $\mathrm{Ac}_{2} \mathrm{O}(5.1 \mathrm{~g}, 50 \mathrm{mmol})$ in $40 \mathrm{ml}$ of $\mathrm{CH}_{2} \mathrm{Cl}_{2}$ was slowly added to a stirred solution of diol $10(5.35 \mathrm{~g}, 60.72 \mathrm{mmol})$ and $\mathrm{Et}_{3} \mathrm{~N}$ (5.06 g, $50.1 \mathrm{mmol}$ ) in $120 \mathrm{ml}$ of $\mathrm{CH}_{2} \mathrm{Cl}_{2}$, and the reaction mixture was stirred for an additional 1 hour. Then, the reaction mixture was washed with saturated aqueous solutions of $\mathrm{NaHCO}_{3}(50 \mathrm{ml})$ and $\mathrm{NaCl}(2 \times 50 \mathrm{ml})$, and the organic layer was dried over $\mathrm{MgSO}_{4}$. The product was purified by column chromatography (eluent petroleum ether-ethyl acetate, $4: 1$ ). Yield $58 \%$. The spectral data for the obtained compound completely correspond to those reported in literature [19].

2.2.10. (3-(Hydroxymethyl)oxirane-2-yl)methyl Acetate (14). Compound 14 was obtained from compound 13 (1.41 g, $10.6 \mathrm{mmol}$ ) using a procedure similar to that used for the synthesis of epoxide 2 . Yield $70 \%(1.1 \mathrm{~g})$, colorless oil. The spectral data for the obtained compound completely correspond to those reported in literature [20].

2.2.11. 3,4-Dihydroxy-2-(phenylthio)butyl Acetate (16) and 2,4-Dihydroxy-3-(phenylthio)butyl Acetate(15). Compounds 15 and 16 were obtained from epoxide $14(0.57 \mathrm{~g}, 3.85 \mathrm{mmol})$ using a procedure similar to that used for the synthesis of dioxepane 3. An inseparable mixture of isomers 15 and 16 in 1 : 1 ratio was obtained as clear oil. Yield 63\% (0.63 g). Mass spectrum (EI) $m / z(\%): 256\left(\mathrm{M}^{+}, 83\right)$. 
2.2.12. (5-(Phenylthio)-1,3-dioxan-4-yl)methanol (9). A mixture of acetates 15 and $16(3.0 \mathrm{~g}, 11.72 \mathrm{mmol})$, paraformaldehyde $(1.0 \mathrm{~g})$, and calcined copper sulfate $(1.0 \mathrm{~g})$ in $\mathrm{CH}_{2} \mathrm{Cl}_{2}$ in the presence of catalytic amounts of $p$-toluenesulfonic acid was stirred at $20^{\circ} \mathrm{C}$ for 48 hours. Copper sulfate was removed by filtration, and the solvent was removed under vacuum. The product was purified by column chromatography (eluent petroleum ether-ethyl acetate, $5: 1$ ).

Yield $24 \%$, colorless crystals, m.p. $85^{\circ} \mathrm{C}-86^{\circ} \mathrm{C} .{ }^{1} \mathrm{H}$ NMR $\left(\mathrm{CDCl}_{3}\right), \delta: 2.2$ br. s $(1 \mathrm{H}, \mathrm{OH}), 3.06-3.09 \mathrm{~m}\left(1 \mathrm{H}, \mathrm{H}^{5},{ }^{3} J\left(\mathrm{H}^{5}\right.\right.$ $\left.\left.\mathrm{H}^{4}\right)=2.3 \mathrm{~Hz},{ }^{3} J\left(\mathrm{H}^{5} \mathrm{H}_{\mathrm{A}}^{6}\right)=2.0 \mathrm{~Hz},{ }^{3} J\left(\mathrm{H}^{5} \mathrm{H}_{\mathrm{B}}^{6}\right)=1.8 \mathrm{~Hz}\right)$, 3.59 dd $\left(1 \mathrm{H}, \quad \mathrm{CH}_{\mathrm{A}} \quad \mathrm{H}_{\mathrm{B}} \mathrm{OH}, \quad{ }^{2} \mathrm{~J}\left(\mathrm{CH}_{\mathrm{A}} \mathrm{H}_{\mathrm{B}} \mathrm{OH}\right.\right.$ $\left.\left.\mathrm{CH}_{\mathrm{A}} \mathrm{H}_{\mathrm{B}} \mathrm{OH}\right)=-11.7 \mathrm{~Hz},{ }^{3} J\left(\mathrm{CH}_{\mathrm{A}} \mathrm{H}_{\mathrm{B}} \mathrm{OH} \quad \mathrm{H}^{4}\right)=4.7 \mathrm{~Hz}\right)$, 3.80-3.87 m (2H, $\mathrm{H}_{\mathrm{A}}^{6}, \quad \mathrm{CH}_{\mathrm{A}} \mathrm{H}_{\mathrm{B}} \mathrm{OH}, \quad{ }^{2} J\left(\mathrm{H}_{\mathrm{A}}^{6}\right.$ $\left.\mathrm{H}^{6}{ }_{\mathrm{B}}\right)=-11.8 \mathrm{~Hz},{ }^{4} J\left(\mathrm{H}_{\mathrm{A}}^{6} \mathrm{H}^{2}{ }_{\mathrm{B}}\right)=-1.0 \mathrm{~Hz},{ }^{3} J\left(\mathrm{CH}_{\mathrm{A}} \mathrm{H}_{\mathrm{B}} \mathrm{OH}\right.$ $\left.\left.\mathrm{H}^{4}\right)=7.7 \mathrm{~Hz}\right), 3.93-3.97 \mathrm{~m}\left(1 \mathrm{H}, \mathrm{H}^{4}\right), 3.99-4.04 \mathrm{~m}(1 \mathrm{H}$, $\left.\mathrm{H}^{6}{ }_{\mathrm{B}}\right), 4.64$ and $5.03\left(\mathrm{AB}, 2 \mathrm{H}, 2 \mathrm{H}^{2},{ }^{2} J\left(\mathrm{H}^{2}{ }_{\mathrm{A}} \mathrm{H}^{2}{ }_{\mathrm{B}}\right)=-6.3 \mathrm{~Hz}\right)$, 7.07-7.35 m $\left(5 \mathrm{H}, \mathrm{C}_{6} \mathrm{H}_{5}\right) .{ }^{13} \mathrm{C} \mathrm{NMR}\left(\mathrm{CDCl}_{3}\right), \delta: 47.27\left(\mathrm{C}^{5}\right)$, $63.80\left(\mathrm{CH}_{2} \mathrm{OH}\right), 70.86\left(\mathrm{C}^{6}\right), 79.48\left(\mathrm{C}^{4}\right), 94.18\left(\mathrm{C}^{2}\right), 127.48$ $\left(\mathrm{C}_{\mathrm{Ar}}\right), 129.31\left(\mathrm{C}_{\mathrm{Ar}}\right), 132.12\left(\mathrm{C}_{\mathrm{Ar}}\right), 134.67\left(\mathrm{C}_{\mathrm{Ar}}\right) . \mathrm{MS}(\mathrm{EI})$ : $m / z(\%)=226\left(\mathrm{M}^{+}, 93\right)$.

\subsubsection{5-Chloro-6-(phenylthio)-1,3-dioxepane (17)}

Method 1. $\mathrm{Et}_{3} \mathrm{~N}(0.6 \mathrm{ml}, 4.3 \mathrm{mmol})$ and $p$-toluenesulfonyl chloride (TsCl) $(0.81 \mathrm{~g}, 4.25 \mathrm{mmol})$ were added to a solution of dioxepane $3(0.96 \mathrm{~g}, 4.25 \mathrm{mmol})$ in $20 \mathrm{ml}$ of $\mathrm{CH}_{2} \mathrm{Cl}_{2}$. The reaction mixture was allowed to stay at $20^{\circ} \mathrm{C}$ for 24 hours. Then, the solvent was removed under vacuum, and the product was purified by column chromatography (eluent petroleum ether-ethyl acetate, $9: 1)$.

Yield $87 \%$ (0.9 g), colorless oil. ${ }^{1} \mathrm{H}$ NMR $\left(\mathrm{CDCl}_{3}\right), \delta$ : $3.23-3.29 \mathrm{~m}\left(1 \mathrm{H}, \mathrm{H}^{6},{ }^{3} J\left(\mathrm{H}^{6} \mathrm{H}^{5}\right)=5.5 \mathrm{~Hz},{ }^{3} J\left(\mathrm{H}^{6} \mathrm{H}_{\mathrm{B}}^{7}\right)=\right.$ $\left.6.3 \mathrm{~Hz},{ }^{3} J\left(\mathrm{H}^{6} \mathrm{H}_{\mathrm{A}}^{7}\right)=2.7 \mathrm{~Hz},{ }^{4} J\left(\mathrm{H}^{6} \mathrm{H}^{4}{ }_{\mathrm{A}}\right)=-1.0 \mathrm{~Hz}\right), 3.72 \mathrm{ddd}$ $\left(1 \mathrm{H}, \mathrm{H}^{4}{ }_{\mathrm{A}},{ }^{2} J\left(\mathrm{H}_{\mathrm{A}}^{4} \mathrm{H}_{\mathrm{B}}^{4}\right)=-12.5 \mathrm{~Hz},{ }^{3} J\left(\mathrm{H}_{\mathrm{A}}^{4} \mathrm{H}^{5}\right)=6.1 \mathrm{~Hz}\right)$, 3.75 ddd $\left(1 \mathrm{H}, \mathrm{H}_{\mathrm{A}}^{7},{ }^{2} J\left(\mathrm{H}_{\mathrm{A}}^{7} \mathrm{H}_{\mathrm{B}}^{7}\right)=-12.4 \mathrm{~Hz}\right), 3.83 \mathrm{dt}(1 \mathrm{H}$, $\left.\mathrm{H}^{5},{ }^{3} J\left(\mathrm{H}^{5} \mathrm{H}^{4}{ }_{\mathrm{B}}\right)=2.2 \mathrm{~Hz}\right), 4.08 \mathrm{dd}\left(1 \mathrm{H}, \mathrm{H}^{7}{ }_{\mathrm{B}}\right), 4.11 \mathrm{dd}(1 \mathrm{H}$, $\left.\mathrm{H}^{4}{ }_{\mathrm{B}}\right), 4.62$ and $4.65\left(\mathrm{AB}, 2 \mathrm{H}, 2 \mathrm{H}^{2},{ }^{2} J\left(\mathrm{H}_{\mathrm{A}}^{2} \mathrm{H}^{2}{ }_{\mathrm{B}}\right)=-4.4 \mathrm{~Hz}\right)$, $7.12-7.35 \mathrm{~m}\left(5 \mathrm{H}, \mathrm{C}_{6} \mathrm{H}_{5}\right) .{ }^{13} \mathrm{C} \mathrm{NMR}\left(\mathrm{CDCl}_{3}\right), \delta: 55.71\left(\mathrm{C}^{6}\right)$, $60.67\left(\mathrm{C}^{7}\right), 65.34\left(\mathrm{C}^{4}\right), 66.89\left(\mathrm{C}^{5}\right)$, $93.93\left(\mathrm{C}^{2}\right), 127.76\left(\mathrm{C}_{\mathrm{Ar}}\right)$, $129.28\left(\mathrm{C}_{\mathrm{Ar}}\right), 132.16\left(\mathrm{C}_{\mathrm{Ar}}\right), 133.01\left(\mathrm{C}_{\mathrm{Ar}}\right) . \mathrm{MS}(\mathrm{EI}): m / z(\%)=$ $244\left(\mathrm{M}^{+}, 83\right), 245\left(\mathrm{M}^{+}, 12\right), 246\left(\mathrm{M}^{+}, 38\right)$.

Method 2. $\mathrm{Et}_{3} \mathrm{~N}(1.33 \mathrm{ml}, 9.5 \mathrm{mmol})$ and methylsulfonyl chloride $(\mathrm{MsCl})(1.15 \mathrm{~g}, 10 \mathrm{mmol})$ were added to a solution of dioxepane $3(2.12 \mathrm{~g}, 9.4 \mathrm{mmol})$ in $20 \mathrm{ml}$ of $\mathrm{CH}_{2} \mathrm{Cl}_{2}$. The reaction mixture was allowed to stay at $20^{\circ} \mathrm{C}$ for 24 hours. Then, the solvent was removed under vacuum, and the product was purified by column chromatography (eluent petroleum etherethyl acetate, 9:1). Yield 76\% (1.75g), colorless oil.

Method 3. $\mathrm{SOCl}_{2}(0.31 \mathrm{~g}, 2.6 \mathrm{mmol})$ was added to a solution of dioxepane $3(0.3 \mathrm{~g}, 1.3 \mathrm{mmol})$ in $30 \mathrm{ml}$ of $\mathrm{CHCl}_{3}$. The mixture was allowed to stay at $20^{\circ} \mathrm{C}$ for 24 hours. Then, the solvent was removed by distillation under vacuum, and the product was purified by column chromatography (eluent petroleum ether-ethyl acetate, 9:1). Yield 52\% (0.17 g), colorless oil.
2.2.14. 5-Methoxy-6-(phenylthio)-1,3-dioxepane (18). $\mathrm{CH}_{3} \mathrm{OH}(30 \mathrm{ml})$ and double molar excess of $\mathrm{NaOH}$ were added to dioxepane $3(1.57 \mathrm{~g}, 6.42 \mathrm{mmol})$, and the reaction mixture was heated on an oil bath under reflux for 10 hours. The solvent was evaporated, and the product was extracted with diethyl ether $(2 \times 10 \mathrm{ml})$ from the residue. The extract was evaporated under vacuum, and the product was purified by column chromatography (eluent petroleum ether-ethyl acetate, $9: 1)$.

Yield 46\% (0.7 g), colorless oil. ${ }^{1} \mathrm{H}$ NMR $\left(\mathrm{CDCl}_{3}\right), \delta: 3.22$ dt $\left(1 \mathrm{H}, \mathrm{H}^{6},{ }^{3} J\left(\mathrm{H}^{6} \mathrm{H}^{5}\right)=4.9 \mathrm{~Hz},{ }^{3} J\left(\mathrm{H}^{6} \mathrm{H}_{\mathrm{A}}^{7}\right)=5.2 \mathrm{~Hz},{ }^{3} J\left(\mathrm{H}^{6}\right.\right.$ $\left.\left.\mathrm{H}^{7}{ }_{\mathrm{B}}\right)=2.2 \mathrm{~Hz}\right), 3.28-3.34 \mathrm{~m}\left(1 \mathrm{H}, \mathrm{H}^{5},{ }^{3} J\left(\mathrm{H}^{5} \mathrm{H}^{4}{ }_{\mathrm{A}}\right)=5.9 \mathrm{~Hz},{ }^{3} J\right.$ $\left.\left(\mathrm{H}^{5} \mathrm{H}_{\mathrm{B}}^{4}\right)=2.5 \mathrm{~Hz},{ }^{4} J\left(\mathrm{H}^{5} \mathrm{H}^{7} \mathrm{~A}\right)=-1.1 \mathrm{~Hz}\right), 3.34 \mathrm{~s}\left(3 \mathrm{H}, \mathrm{CH}_{3}\right)$, 3.75-3.87 m (1H, $\mathrm{H}_{\mathrm{A}}^{4}, \mathrm{H}_{\mathrm{A}}^{7},{ }^{2} J\left(\mathrm{H}_{\mathrm{A}}^{4} \mathrm{H}_{\mathrm{B}}^{4}\right)=-12.3 \mathrm{~Hz},{ }^{2} J$ $\left.\left(\mathrm{H}_{\mathrm{A}}^{7} \mathrm{H}_{\mathrm{B}}^{7}\right)=-12.6 \mathrm{~Hz}\right), 3.96 \mathrm{dd}\left(1 \mathrm{H}, \mathrm{H}^{7}{ }_{\mathrm{B}}\right), 4.05 \mathrm{dd}(1 \mathrm{H}$, $\left.\mathrm{H}_{\mathrm{B}}^{4}\right), 4.69$ and $4.73\left(\mathrm{AB}, 2 \mathrm{H}, 2 \mathrm{H}^{2},{ }^{2} J\left(\mathrm{H}^{2}{ }_{\mathrm{A}} \mathrm{H}^{2}{ }_{\mathrm{B}}\right)=-4.45 \mathrm{~Hz}\right)$, 7.17-7.44 m (5H, $\left.\mathrm{C}_{6} \mathrm{H}_{5}\right) .{ }^{13} \mathrm{C} \mathrm{NMR}\left(\mathrm{CDCl}_{3}\right), \delta: 52.41\left(\mathrm{C}^{6}\right)$, $57.43\left(\mathrm{CH}_{3}\right), 64.63\left(\mathrm{C}^{7}\right), 65.32\left(\mathrm{C}^{4}\right), 81.37\left(\mathrm{C}^{5}\right), 94.46\left(\mathrm{C}^{2}\right)$, $127.24\left(\mathrm{C}_{\mathrm{Ar}}\right), 129.15\left(\mathrm{C}_{\mathrm{Ar}}\right), 131.67\left(\mathrm{C}_{\mathrm{Ar}}\right), 134.35\left(\mathrm{C}_{\mathrm{Ar}}\right) . \mathrm{MS}$ (EI): $m / z(\%)=240\left(\mathrm{M}^{+}, 86\right)$.

2.2.15. 3,5-Dioxa-8-thiabicyclo[5.1.0]octane (19). A mixture of epoxide 2 ( $1 \mathrm{~g}, 8.62 \mathrm{mmol}), \mathrm{CS}\left(\mathrm{NH}_{2}\right)_{2}(0.66 \mathrm{~g}, 8.62 \mathrm{mmol})$, $0.2 \mathrm{ml}$ of concentrated $\mathrm{H}_{2} \mathrm{SO}_{4}$, and $2.5 \mathrm{ml}$ of water was stirred for 10 minutes at $20^{\circ} \mathrm{C}$. Then, the solution of $0.8 \mathrm{~g}$ of $\mathrm{K}_{2} \mathrm{CO}_{3}$ in $4 \mathrm{ml}$ of water was added dropwise to the reaction mixture. The product was extracted with benzene $(3 \times 5 \mathrm{ml})$, and the extract was dried over $\mathrm{MgSO}_{4}$. The solvent was removed on a rotary evaporator at $20^{\circ} \mathrm{C}$. Yield $68 \%(0.77 \mathrm{~g})$, colorless crystals. The spectral data for the obtained compound completely correspond to those reported in literature [28].

2.2.16. 6-(Phenylthio)-1,3-dioxepan-5-thiol (20). A mixture of thiophenol $(0.45 \mathrm{~g}, 4.1 \mathrm{mmol})$, thiirane 19 (0.53 g, $4.02 \mathrm{mmol}$ ), and a catalytic amount of $\mathrm{K}_{2} \mathrm{CO}_{3}$ was heated until the appearance of first bubbles. The heating source was removed, and a short-time $(<1$ minute) spontaneous boiling-up with a sharp increase of the temperature was observed. The reaction mixture was cooled, and the product was purified by column chromatography (eluent petroleum ether-ethyl acetate, 9:1).

Yield $62 \%(0.6 \mathrm{~g})$, colorless oil. ${ }^{1} \mathrm{H} \mathrm{NMR}\left(\mathrm{CDCl}_{3}\right), \delta$ : $2.02 \mathrm{~d}\left(1 \mathrm{H}, \mathrm{SH},{ }^{3} \mathrm{~J}\left(\mathrm{SH} \mathrm{H}^{5}\right)=7.9 \mathrm{~Hz}\right), 2.77-2.86 \mathrm{~m}\left(1 \mathrm{H}, \mathrm{H}^{5},{ }^{3} \mathrm{~J}\right.$ $\left(\mathrm{H}^{5} \mathrm{H}^{6}\right)=6.4 \mathrm{~Hz},{ }^{3} J\left(\mathrm{H}^{5} \mathrm{H}_{\mathrm{A}}{ }\right)=6.8 \mathrm{~Hz},{ }^{3} J\left(\mathrm{H}^{5} \mathrm{H}_{\mathrm{B}}^{4}\right)=2.8 \mathrm{~Hz},{ }^{4} J$ $\left.\left(\mathrm{H}^{5} \mathrm{H}_{\mathrm{A}}^{7}\right)=-0.7 \mathrm{~Hz}\right), 3.05 \mathrm{dt}\left(1 \mathrm{H}, \mathrm{H}^{6},{ }^{3} \mathrm{~J}\left(\mathrm{H}^{6} \mathrm{H}_{\mathrm{A}}^{7}\right)=7.0 \mathrm{~Hz},{ }^{3} \mathrm{~J}\right.$ $\left.\left(\mathrm{H}^{6} \mathrm{H}_{\mathrm{B}}^{7}\right)=2.8 \mathrm{~Hz},{ }^{4} J\left(\mathrm{H}^{6} \mathrm{H}^{4}{ }_{\mathrm{A}}\right)=-0.7 \mathrm{~Hz}\right), 3.54 \mathrm{dd}\left(1 \mathrm{H}, \mathrm{H}^{4}{ }_{\mathrm{A}}\right.$, $\left.{ }^{2} J\left(\mathrm{H}_{\mathrm{A}}^{4} \mathrm{H}_{\mathrm{B}}^{4}\right)=-12.1 \mathrm{~Hz}\right), \quad 3.67 \mathrm{dd}\left(1 \mathrm{H}, \mathrm{H}_{\mathrm{A}}^{7},{ }^{2} J\left(\mathrm{H}_{\mathrm{A}}^{7}\right.\right.$ $\left.\left.\mathrm{H}^{7}{ }_{\mathrm{B}}\right)=-12.3 \mathrm{~Hz}\right), 3.94 \mathrm{dd}\left(1 \mathrm{H}_{,} \mathrm{H}^{7}{ }_{\mathrm{B}}\right), 3.99 \mathrm{dd}\left(1 \mathrm{H}, \mathrm{H}^{4}{ }_{\mathrm{B}}\right), 4.55$ and $4.65\left(\mathrm{AB}, 2 \mathrm{H}, 2 \mathrm{H}^{2},{ }^{2} J\left(\mathrm{H}_{\mathrm{A}}^{2} \mathrm{H}^{2}{ }_{\mathrm{B}}\right)=-4.3 \mathrm{~Hz}\right), 7.03-$ $7.31 \mathrm{~m}\left(5 \mathrm{H}, \mathrm{C}_{6} \mathrm{H}_{5}\right) .{ }^{13} \mathrm{C} \mathrm{NMR}\left(\mathrm{CDCl}_{3}\right), \delta: 43.31\left(\mathrm{C}^{5}\right), 56.78$ $\left(\mathrm{C}^{6}\right), 66.39\left(\mathrm{C}^{7}\right), 67.64\left(\mathrm{C}^{4}\right), 93.80\left(\mathrm{C}^{2}\right), 127.53\left(\mathrm{C}_{\mathrm{Ar}}\right), 129.13$ $\left(\mathrm{C}_{\mathrm{Ar}}\right), 132.20\left(\mathrm{C}_{\mathrm{Ar}}\right), 133.36\left(\mathrm{C}_{\mathrm{Ar}}\right)$. $\mathrm{MS}(\mathrm{EI}): m / z(\%)=242$ $\left(\mathrm{M}^{+}, 5\right)$.

2.2.17. 6-(Benzylthio)-1,3-dioxepan-5-ol (21). Compound 21 was obtained from epoxide $2(1.12 \mathrm{~g}, 9.66 \mathrm{mmol})$ using 
a procedure similar to that used for the synthesis of compound 3. $\mathrm{NaOH}$ was used instead of $\mathrm{K}_{2} \mathrm{CO}_{3}$.

Yield $71 \%(1.64 \mathrm{~g})$, colorless oil. ${ }^{1} \mathrm{H}$ NMR $\left(\mathrm{CDCl}_{3}\right), \delta$ : $2.68-2.73 \mathrm{~m}\left(1 \mathrm{H}, \mathrm{H}^{6},{ }^{3} J\left(\mathrm{H}^{6} \mathrm{H}^{5}\right)=6.0 \mathrm{~Hz},{ }^{3} J\left(\mathrm{H}^{6} \mathrm{H}_{\mathrm{A}}^{7}\right)=\right.$ $\left.6.7 \mathrm{~Hz},{ }^{3} J\left(\mathrm{H}^{6} \mathrm{H}_{\mathrm{B}}{ }_{\mathrm{B}}\right)=3.0 \mathrm{~Hz},{ }^{4} J\left(\mathrm{H}^{6} \mathrm{H}_{\mathrm{A}}^{4}\right)=-0.9 \mathrm{~Hz}\right), 2.78 \mathrm{br} . \mathrm{s}$ $(1 \mathrm{H}, \mathrm{OH}), 3.62 \mathrm{dt}\left(1 \mathrm{H}, \mathrm{H}^{5},{ }^{3} J\left(\mathrm{H}^{5} \mathrm{H}^{4}{ }_{\mathrm{A}}\right)=6.2 \mathrm{~Hz},{ }^{3} J\left(\mathrm{H}^{5}\right.\right.$ $\left.\left.\mathrm{H}_{\mathrm{B}}^{4}\right)=2.1 \mathrm{~Hz}\right), 3.67 \mathrm{dd}\left(1 \mathrm{H}, \mathrm{H}_{\mathrm{A}}^{7},{ }^{2} J\left(\mathrm{H}_{\mathrm{A}}^{7} \mathrm{H}_{\mathrm{B}}^{7}\right)=-12.4 \mathrm{~Hz}\right)$, 3.70 ddd $\left(1 \mathrm{H}, \mathrm{H}_{\mathrm{A}}^{4},{ }^{2} J\left(\mathrm{H}^{4}{ }_{\mathrm{A}} \mathrm{H}_{\mathrm{B}}^{4}\right)=-11.9 \mathrm{~Hz}\right), 3.78 \mathrm{~s}(2 \mathrm{H}$, $\left.\mathrm{CH}_{2} \mathrm{~S}\right), 3.88 \mathrm{dd}\left(1 \mathrm{H}, \mathrm{H}_{\mathrm{B}}^{7}\right), 4.00 \mathrm{dd}\left(1 \mathrm{H}, \mathrm{H}_{\mathrm{B}}^{4}\right), 4.70$ and 4.72 $\left(\mathrm{AB}, 2 \mathrm{H}, 2 \mathrm{H}^{2},{ }^{2} J\left(\mathrm{H}^{2} \mathrm{~A} \mathrm{H}^{2}{ }_{\mathrm{B}}\right)=-4.5 \mathrm{~Hz}\right), 7.23-7.39 \mathrm{~m}(5 \mathrm{H}$, $\left.\mathrm{C}_{6} \mathrm{H}_{5}\right) \cdot{ }^{13} \mathrm{C}$ NMR $\left(\mathrm{CDCl}_{3}\right), \delta: 35.83\left(\mathrm{CH}_{2} \mathrm{~S}\right), 51.71\left(\mathrm{C}^{6}\right), 65.93$ $\left(\mathrm{C}^{7}\right), 66.77\left(\mathrm{C}^{4}\right), 72.03\left(\mathrm{C}^{5}\right), 94.25\left(\mathrm{C}^{2}\right), 127.45\left(\mathrm{C}_{\mathrm{Ar}}\right), 128.80$ $\left(\mathrm{C}_{\mathrm{Ar}}\right), 128.89\left(\mathrm{C}_{\mathrm{Ar}}\right), 138.16\left(\mathrm{C}_{\mathrm{Ar}}\right)$. MS (EI): $m / z(\%)=240$ $\left(\mathrm{M}^{+}, 51\right)$.

2.2.18. 6-Phenoxy-1,3-dioxepan-5-ol (22). Compound 22 was obtained from epoxide $2(0.75 \mathrm{~g}, 6.47 \mathrm{mmol})$ using a procedure similar to that used for the synthesis of compound 3.

Yield $81 \%(1.1 \mathrm{~g})$, colorless oil. ${ }^{1} \mathrm{H}$ NMR $\left(\mathrm{CDCl}_{3}\right), \delta: 3.30$ br. d $\left(1 \mathrm{H}, \mathrm{OH},{ }^{3} \mathrm{~J}\left(\mathrm{OH} \mathrm{H}^{5}\right)=7.4 \mathrm{~Hz}\right), 3.77$ ddd $\left(1 \mathrm{H}, \mathrm{H}^{7}{ }_{\mathrm{A}},{ }^{2} J\right.$

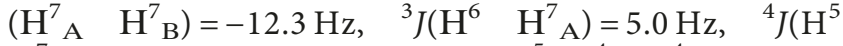
$\left.\left.\mathrm{H}_{\mathrm{A}}^{7}\right)=-0.8 \mathrm{~Hz}\right), 3.87-3.96 \mathrm{~m}\left(3 \mathrm{H}, \mathrm{H}^{5}, \mathrm{H}_{\mathrm{A}}^{4} \mathrm{H}_{\mathrm{B}}^{4}\right), 4.03 \mathrm{dd}$ $\left(1 \mathrm{H}, \mathrm{H}_{\mathrm{B}}^{7},{ }^{3} J\left(\mathrm{H}^{6} \mathrm{H}_{\mathrm{B}}^{7}\right)=1.8 \mathrm{~Hz}\right), 4.31-4.35 \mathrm{~m}\left(1 \mathrm{H}, \mathrm{H}^{6}\right), 4.77$ and $4.80\left(\mathrm{AB}, 2 \mathrm{H}, 2 \mathrm{H}^{2},{ }^{2} J\left(\mathrm{H}^{2} \mathrm{~A} \mathrm{H}_{\mathrm{B}} \mathrm{H}^{2}=-4.7 \mathrm{~Hz}\right), 6.94-7.32 \mathrm{~m}\right.$ $\left(5 \mathrm{H}, \mathrm{C}_{6} \mathrm{H}_{5}\right) .{ }^{13} \mathrm{C}$ NMR $\left(\mathrm{CDCl}_{3}\right), \delta: 64.50\left(\mathrm{C}^{4}\right), 65.53\left(\mathrm{C}^{7}\right), 70.97$ $\left(\mathrm{C}^{5}\right), 78.94\left(\mathrm{C}^{6}\right), 94.59\left(\mathrm{C}^{2}\right), 115.96\left(\mathrm{C}_{\mathrm{Ar}}\right), 121.61\left(\mathrm{C}_{\mathrm{Ar}}\right), 129.68$ $\left(\mathrm{C}_{\mathrm{Ar}}\right), 157.07\left(\mathrm{C}_{\mathrm{Ar}}\right)$. MS (EI): $m / z(\%)=210\left(\mathrm{M}^{+}, 71\right)$.

2.2.19. 6-(Phenylamino)-1,3-dioxepan-5-ol (23). Compound 23 was obtained from epoxide $2(0.36 \mathrm{~g}, 3.10 \mathrm{mmol})$ using a procedure similar to that used for the synthesis of compound 3. $\mathrm{NaOH}$ was used instead of $\mathrm{K}_{2} \mathrm{CO}_{3}$.

Yield $29 \%(0.19 \mathrm{~g})$, yellow oil. ${ }^{1} \mathrm{H}$ NMR $\left(\mathrm{CDCl}_{3}\right), \delta: 2.80$ br. s $(1 \mathrm{H}, \mathrm{OH}), 3.52-3.56 \mathrm{~m}\left(1 \mathrm{H}, \mathrm{H}^{6}\right), 3.74-3.91 \mathrm{~m}\left(4 \mathrm{H}, \mathrm{H}^{5}\right.$, $\left.\mathrm{H}_{\mathrm{A}}^{4}, \mathrm{H}_{\mathrm{A}}{ }_{\mathrm{A}}, \mathrm{H}^{7}{ }_{\mathrm{B}}\right), 4.00 \mathrm{dd}\left(1 \mathrm{H}, \mathrm{H}_{\mathrm{B}}^{4},{ }^{2} J\left(\mathrm{H}_{\mathrm{A}}^{4} \mathrm{H}_{\mathrm{B}}^{4}\right)=-12.2 \mathrm{~Hz}\right.$, $\left.{ }^{4} J\left(\mathrm{H}^{6} \mathrm{H}^{4}{ }_{\mathrm{B}}\right)=-1.5 \mathrm{~Hz}\right), 4.31$ br. $\mathrm{s}(1 \mathrm{H}, \mathrm{NH}), 4.78$ and 4.80 $\left(\mathrm{AB}, 2 \mathrm{H}, \mathrm{H}^{2},{ }^{2} J\left(\mathrm{H}^{2}{ }_{\mathrm{A}} \mathrm{H}_{\mathrm{B}}{ }_{\mathrm{B}}\right)=-4.4 \mathrm{~Hz}\right), 6.64-7.23 \mathrm{~m}(5 \mathrm{H}$, $\left.\mathrm{C}_{6} \mathrm{H}_{5}\right) \cdot{ }^{13} \mathrm{C}$ NMR $\left(\mathrm{CDCl}_{3}\right), \delta: 56.98\left(\mathrm{C}^{6}\right), 64.41\left(\mathrm{C}^{7}\right), 65.57$ $\left(\mathrm{C}^{4}\right), 69.98\left(\mathrm{C}^{5}\right), 94.20\left(\mathrm{C}^{2}\right), 113.04\left(\mathrm{C}_{\mathrm{Ar}}\right), 117.73\left(\mathrm{C}_{\mathrm{Ar}}\right)$, $129.63\left(\mathrm{C}_{\mathrm{Ar}}\right), 146.12\left(\mathrm{C}_{\mathrm{Ar}}\right)$. MS (EI): $m / z(\%)=209\left(\mathrm{M}^{+}, 61\right)$.

2.2.20. 6-(o-Tolylthio)-1,3-dioxepan-5-ol (24). Epoxide 2 $(0.2 \mathrm{~g}, 1.72 \mathrm{mmol})$ was added to a solution of $o$-toluenethiol $(0.257 \mathrm{~g}, 2.07 \mathrm{mmol})$ and $\mathrm{NaOH}(0.083 \mathrm{~g}, 2.07 \mathrm{mmol})$ in $30 \mathrm{ml}$ of methanol, and the reaction mixture was stirred at $50^{\circ} \mathrm{C}$ for 3 hours. The solvent was evaporated, and the product was extracted with diethyl ether $(2 \times 10 \mathrm{ml})$ from the residue. The extract was concentrated under vacuum, and the product was purified by column chromatography (eluent petroleum ether-ethyl acetate, $4: 1)$.

Yield $85 \%(0.35 \mathrm{~g})$, yellow oil. ${ }^{1} \mathrm{H}$ NMR $\left(\mathrm{CDCl}_{3}\right), \delta$ : $2.43 \mathrm{~s}\left(1 \mathrm{H}, \mathrm{CH}_{3}\right), 2.93$ br. s $(1 \mathrm{H}, \mathrm{OH}), 3.21-3.25 \mathrm{~m}(1 \mathrm{H}$, $\mathrm{H}^{6},{ }^{3} J\left(\mathrm{H}^{6} \mathrm{H}^{5}\right)=5.5 \mathrm{~Hz},{ }^{3} J\left(\mathrm{H}^{6} \mathrm{H}_{\mathrm{A}} \mathrm{A}\right)=5.8 \mathrm{~Hz},{ }^{3} J\left(\mathrm{H}^{6} \mathrm{H}^{7}{ }_{\mathrm{B}}\right)=$ $\left.2.7 \mathrm{~Hz},{ }^{4} J\left(\mathrm{H}^{6} \mathrm{H}^{4}{ }_{\mathrm{A}}\right)=-0.9 \mathrm{~Hz}\right), 3.72 \mathrm{dt}\left(1 \mathrm{H}, \mathrm{H}^{5},{ }^{3} J\left(\mathrm{H}^{5} \mathrm{H}^{4}{ }_{\mathrm{A}}\right)=\right.$ $\left.5.7 \mathrm{~Hz},{ }^{3} J\left(\mathrm{H}^{5} \mathrm{H}_{\mathrm{B}}^{4}\right)=1.6 \mathrm{~Hz}\right), 3.78$ ddd $\left(1 \mathrm{H}, \mathrm{H}^{4}{ }_{\mathrm{A}},{ }^{2} J\left(\mathrm{H}_{\mathrm{A}}^{4}\right.\right.$ $\left.\left.\mathrm{H}_{\mathrm{B}}^{4}\right)=-11.9 \mathrm{~Hz}\right), 3.87 \mathrm{dd}\left(1 \mathrm{H}, \mathrm{H}_{\mathrm{A}}^{7},{ }^{2} J\left(\mathrm{H}_{\mathrm{A}}^{7} \mathrm{H}_{\mathrm{B}}^{7}\right)=-12.5 \mathrm{~Hz}\right)$,
$4.04 \mathrm{dd}\left(1 \mathrm{H}, \mathrm{H}_{\mathrm{B}}{ }^{\mathrm{B}}\right), 4.13 \mathrm{dd}\left(1 \mathrm{H}, \mathrm{H}_{\mathrm{B}}^{4}\right), 4.76$ and $4.77(\mathrm{AB}, 2 \mathrm{H}$, $\left.2 \mathrm{H}^{2},{ }^{2} J\left(\mathrm{H}^{2}{ }_{\mathrm{A}} \mathrm{H}^{2}{ }_{\mathrm{B}}\right)=-4.9 \mathrm{~Hz}\right), 7.13-7.44 \mathrm{~m}\left(4 \mathrm{H}, 2-\mathrm{CH}_{3} \mathrm{C}_{6} \mathrm{H}_{4}\right)$. ${ }^{13} \mathrm{C}$ NMR $\left(\mathrm{CDCl}_{3}\right), \delta: 20.90\left(\mathrm{CH}_{3}\right), 54.13\left(\mathrm{C}^{6}\right), 65.42\left(\mathrm{C}^{7}\right), 66.50$ $\left(\mathrm{C}^{4}\right), 71.73\left(\mathrm{C}^{5}\right), 94.38\left(\mathrm{C}^{2}\right), 126.77\left(\mathrm{C}_{\mathrm{Ar}}\right), 127.38\left(\mathrm{C}_{\mathrm{Ar}}\right), 130.66$ $\left(\mathrm{C}_{\mathrm{Ar}}\right), 131.41\left(\mathrm{C}_{\mathrm{Ar}}\right), 132.99\left(\mathrm{C}_{\mathrm{Ar}}\right), 139.56\left(\mathrm{C}_{\mathrm{Ar}}\right) . \mathrm{MS}(\mathrm{EI}): \mathrm{m} / \mathrm{z}$ $(\%)=240\left(\mathrm{M}^{+}, 39\right)$.

2.2.21. 6-(p-Tolylthio)-1,3-dioxepan-5-ol (25). Compound 25 was obtained from epoxide $2(0.2 \mathrm{~g}, 1.72 \mathrm{mmol})$ using a procedure similar to that used for the synthesis of compound 24.

Yield $88 \%\left(0.36\right.$ g), colorless crystals, m.p. $54-55^{\circ} \mathrm{C} .{ }^{1} \mathrm{H}$ NMR $\left(\mathrm{CDCl}_{3}\right), \delta: 2.33 \mathrm{~s}\left(1 \mathrm{H}, \mathrm{CH}_{3}\right), 2.80$ br. s $(1 \mathrm{H}, \mathrm{OH})$, $3.10-3.14 \mathrm{~m}\left(1 \mathrm{H}, \mathrm{H}^{6},{ }^{3} J\left(\mathrm{H}^{6} \mathrm{H}^{5}\right)=6.0 \mathrm{~Hz},{ }^{3} J\left(\mathrm{H}^{6} \mathrm{H}_{\mathrm{A}}^{7}\right)=\right.$ $\left.6.7 \mathrm{~Hz},{ }^{3} J\left(\mathrm{H}^{6} \mathrm{H}^{7}{ }_{\mathrm{B}}\right)=2.9 \mathrm{~Hz},{ }^{4} J\left(\mathrm{H}^{6} \mathrm{H}^{4}{ }_{\mathrm{A}}\right)=-0.7 \mathrm{~Hz}\right), 3.66 \mathrm{dt}$ $\left(1 \mathrm{H}, \mathrm{H}^{5},{ }^{3} J\left(\mathrm{H}^{5} \mathrm{H}_{\mathrm{A}}^{4}\right)=6.2 \mathrm{~Hz},{ }^{3} J\left(\mathrm{H}^{5} \mathrm{H}_{\mathrm{B}}^{4}\right)=2.1 \mathrm{~Hz}\right), 3.73$ ddd $\left(1 \mathrm{H}, \mathrm{H}_{\mathrm{A}}^{4},{ }^{2} J\left(\mathrm{H}_{\mathrm{A}}^{4} \mathrm{H}_{\mathrm{B}}^{4}\right)=-11.8 \mathrm{~Hz}\right), 3.79 \mathrm{dd}\left(1 \mathrm{H}, \mathrm{H}_{\mathrm{A}}^{7}\right.$, $\left.{ }^{2} \mathrm{~J}\left(\mathrm{H}_{\mathrm{A}}^{7} \mathrm{H}_{\mathrm{B}}^{7}\right)=-12.4 \mathrm{~Hz}\right), 4.04 \mathrm{dd}\left(1 \mathrm{H}, \mathrm{H}_{\mathrm{B}}^{7}\right), 4.08 \mathrm{dd}(1 \mathrm{H}$, $\left.\mathrm{H}^{4}{ }_{\mathrm{B}}\right), 4.72$ and $4.75\left(\mathrm{AB}, 2 \mathrm{H}, 2 \mathrm{H}^{2},{ }^{2} J\left(\mathrm{H}^{2}{ }_{\mathrm{A}} \mathrm{H}_{\mathrm{B}}^{2}\right)=-4.5 \mathrm{~Hz}\right)$, 7.09-7.37 m (4H, 4- $\left.\mathrm{CH}_{3} \mathrm{C}_{6} \mathrm{H}_{4}\right) .{ }^{13} \mathrm{C} \mathrm{NMR}\left(\mathrm{CDCl}_{3}\right), \delta: 21.19$ $\left(\mathrm{CH}_{3}\right), 55.41\left(\mathrm{C}^{6}\right), 65.74\left(\mathrm{C}^{7}\right), 66.60\left(\mathrm{C}^{4}\right), 71.51\left(\mathrm{C}^{5}\right), 94.31$ $\left(\mathrm{C}^{2}\right), 129.28\left(\mathrm{C}_{\mathrm{Ar}}\right), 130.07\left(\mathrm{C}_{\mathrm{Ar}}\right), 132.98\left(\mathrm{C}_{\mathrm{Ar}}\right), 138.07\left(\mathrm{C}_{\mathrm{Ar}}\right)$. MS (EI): $m / z(\%)=240\left(\mathrm{M}^{+}, 51\right)$.

2.2.22. 6-((2-Chlorophenyl)thio)-1,3-dioxepan-5-ol (26). Compound 26 was obtained from epoxide $2(0.2 \mathrm{~g}, 1.72 \mathrm{mmol})$ using a procedure similar to that used for the synthesis of compound 24.

Yield 68\% (0.31 g), yellow oil. ${ }^{1} \mathrm{H}$ NMR $\left(\mathrm{CDCl}_{3}\right), \delta: 3.08$ br. s $(1 \mathrm{H}, \mathrm{OH}), 3.28-3.32 \mathrm{~m}\left(1 \mathrm{H}, \mathrm{H}^{6},{ }^{3} J\left(\mathrm{H}^{6} \mathrm{H}^{5}\right)=5.3 \mathrm{~Hz}\right.$, ${ }^{3} J\left(\mathrm{H}^{6} \quad \mathrm{H}_{\mathrm{A}}^{7}\right)=5.7 \mathrm{~Hz},{ }^{3} J\left(\mathrm{H}^{6} \quad \mathrm{H}_{\mathrm{B}}^{7}\right)=2.7 \mathrm{~Hz},{ }^{4} J\left(\mathrm{H}^{6}\right.$ $\left.\left.\mathrm{H}_{\mathrm{A}}^{4}\right)=-1.1 \mathrm{~Hz}\right), 3.68-3.74$ br. $\mathrm{m}\left(1 \mathrm{H}, \mathrm{H}^{5},{ }^{3} J\left(\mathrm{H}^{5} \mathrm{H}^{4}{ }_{\mathrm{A}}\right)=\right.$ $\left.5.5 \mathrm{~Hz},{ }^{3} J\left(\mathrm{H}^{5} \mathrm{H}_{\mathrm{B}}^{4}\right)=1.7 \mathrm{~Hz}\right), 3.77 \mathrm{ddd}\left(1 \mathrm{H}, \mathrm{H}^{4}{ }_{\mathrm{A}},{ }^{2} J\left(\mathrm{H}_{\mathrm{A}}^{4}\right.\right.$ $\left.\left.\mathrm{H}_{\mathrm{B}}^{4}\right)=-12.1 \mathrm{~Hz}\right), 3.91 \mathrm{ddd}\left(1 \mathrm{H}, \mathrm{H}_{\mathrm{A}}^{7},{ }^{2} J\left(\mathrm{H}_{\mathrm{A}}^{7} \mathrm{H}_{\mathrm{B}}^{7}\right)=-12.6 \mathrm{~Hz}\right.$, $\left.{ }^{4} J\left(\mathrm{H}_{\mathrm{A}}^{7} \mathrm{H}^{5}\right)=-0.5 \mathrm{~Hz}\right), 4.07 \mathrm{dd}\left(1 \mathrm{H}, \mathrm{H}^{7}{ }_{\mathrm{B}}\right), 4.13 \mathrm{dd}\left(1 \mathrm{H}, \mathrm{H}_{\mathrm{B}}^{4}\right)$, 4.75 and $4.76\left(\mathrm{AB}, 2 \mathrm{H}, 2 \mathrm{H}^{2},{ }^{2} J\left(\mathrm{H}_{\mathrm{A}}{ }_{\mathrm{A}} \mathrm{H}^{2}{ }_{\mathrm{B}}\right)=-4.5 \mathrm{~Hz}\right), 7.16-$ $7.48 \mathrm{~m}\left(4 \mathrm{H}, 2-\mathrm{ClC}_{6} \mathrm{H}_{4}\right) \cdot{ }^{13} \mathrm{C}$ NMR $\left(\mathrm{CDCl}_{3}\right), \delta: 53.85\left(\mathrm{C}^{6}\right), 65.23$ $\left(C^{7}\right), 66.49\left(C^{4}\right), 71.57\left(C^{5}\right), 94.39\left(C^{2}\right), 127.46\left(C_{A r}\right), 128.51$ $\left(\mathrm{C}_{\mathrm{Ar}}\right), 130.28\left(\mathrm{C}_{\mathrm{Ar}}\right), 132.50\left(\mathrm{C}_{\mathrm{Ar}}\right), 132.97\left(\mathrm{C}_{\mathrm{Ar}}\right), 136.23\left(\mathrm{C}_{\mathrm{Ar}}\right)$. MS (EI): $m / z(\%)=260\left(\mathbf{M}^{+}, 53\right), 262\left(\mathbf{M}^{+}, 24\right)$.

2.2.23. 6-((4-Chlorophenyl)thio)-1,3-dioxepan-5-ol (27). Compound 27 was obtained from epoxide $2(0.2 \mathrm{~g}, 1.72 \mathrm{mmol})$ using a procedure similar to that used for the synthesis of compound 24.

Yield $88 \%(0.4 \mathrm{~g})$, colorless crystals, m.p. $67-68^{\circ} \mathrm{C} .{ }^{1} \mathrm{H}$ $\mathrm{NMR}\left(\mathrm{CDCl}_{3}\right), \delta: 2.79 \mathrm{dd}\left(1 \mathrm{H}, \mathrm{OH},{ }^{3} J\left(\mathrm{OHH}^{5}\right)=6.8 \mathrm{~Hz}\right.$, $\left.{ }^{4} J=-1.4 \mathrm{~Hz}\right), 3.02-3.06 \mathrm{~m}\left(1 \mathrm{H}, \mathrm{H}^{6},{ }^{3} J\left(\mathrm{H}^{6} \mathrm{H}^{5}\right)=5.7 \mathrm{~Hz},{ }^{3} J\left(\mathrm{H}^{6}\right.\right.$ $\left.\left.\mathrm{H}^{7} \mathrm{~A}\right)=6.0 \mathrm{~Hz},{ }^{3} J\left(\mathrm{H}^{6} \mathrm{H}^{7}{ }_{\mathrm{B}}\right)=2.7 \mathrm{~Hz}\right), 3.50-3.55$ br. $\mathrm{m}(1 \mathrm{H}$, $\left.\mathrm{H}^{5},{ }^{3} J\left(\mathrm{H}^{5} \mathrm{H}_{\mathrm{A}}^{4}\right)=5.7 \mathrm{~Hz},{ }^{3} J\left(\mathrm{H}^{5} \mathrm{H}_{\mathrm{B}}^{4}\right)=1.8 \mathrm{~Hz}\right), 3.61 \mathrm{ddd}$ $\left(1 \mathrm{H}, \mathrm{H}^{4}{ }_{\mathrm{A}},{ }^{2} J\left(\mathrm{H}^{4}{ }_{\mathrm{A}} \mathrm{H}_{\mathrm{B}}^{4}\right)=-12.1 \mathrm{~Hz},{ }^{4} J\left(\mathrm{H}_{\mathrm{A}}^{4} \mathrm{H}^{6}\right)=-0.8 \mathrm{~Hz}\right)$, $3.69 \mathrm{dd}\left(1 \mathrm{H}, \mathrm{H}_{\mathrm{A}}^{7},{ }^{2} J\left(\mathrm{H}_{\mathrm{A}}^{7} \mathrm{H}_{\mathrm{B}}^{7}\right)=-12.6 \mathrm{~Hz}\right), 3.90 \mathrm{dd}(1 \mathrm{H}$, $\left.\mathrm{H}^{7}{ }_{\mathrm{B}}\right), 3.93 \mathrm{dd}\left(1 \mathrm{H}, \mathrm{H}^{4}{ }_{\mathrm{B}}\right), 4.59$ and $4.61\left(\mathrm{AB}, 2 \mathrm{H}, 2 \mathrm{H}^{2}\right.$, $\left.{ }^{2} J\left(\mathrm{H}_{\mathrm{A}}^{2} \mathrm{H}_{\mathrm{B}}^{2}\right)=-4.5 \mathrm{~Hz}\right), 7.10-7.24 \mathrm{~m}\left(4 \mathrm{H}, 4-\mathrm{ClC}_{6} \mathrm{H}_{4}\right) .{ }^{13} \mathrm{C}$ NMR $\left(\mathrm{CDCl}_{3}\right), \delta$ : $55.13\left(\mathrm{C}^{6}\right), 65.35\left(\mathrm{C}^{7}\right), 66.40\left(\mathrm{C}^{4}\right), 71.49$ $\left(\mathrm{C}^{5}\right), 94.32\left(\mathrm{C}^{2}\right), 129.46\left(\mathrm{C}_{\mathrm{Ar}}\right), 32.01\left(\mathrm{C}_{\mathrm{Ar}}\right), 133.27\left(\mathrm{C}_{\mathrm{Ar}}\right)$, $133.79\left(\mathrm{C}_{\mathrm{Ar}}\right)$. MS (EI): $m / z(\%)=260\left(\mathrm{M}^{+}, 61\right), 262\left(\mathrm{M}^{+}, 28\right)$. 
2.2.24. 6-((2,4-Dichlorophenyl)thio)-1,3-dioxepan-5-ol (28). Compound 28 was obtained from epoxide $2(0.2 \mathrm{~g}, 1.72 \mathrm{mmol})$ using a procedure similar to that used for the synthesis of compound 24.

Yield $80 \%$ (0.40 g), colorless crystals, m.p. $70-71^{\circ} \mathrm{C} .{ }^{1} \mathrm{H}$ $\operatorname{NMR}\left(\mathrm{CDCl}_{3}\right), \delta: 3.13$ br. d $\left(1 \mathrm{H}, \mathrm{OH},{ }^{3} J\left(\mathrm{OHH}^{5}\right)=5.6 \mathrm{~Hz}\right)$, $3.24-3.28 \mathrm{~m}\left(1 \mathrm{H}, \mathrm{H}^{6},{ }^{3} J\left(\mathrm{H}^{6} \mathrm{H}_{\mathrm{A}}^{7}\right)=5.4 \mathrm{~Hz},{ }^{3} J\left(\mathrm{H}^{6} \mathrm{H}_{\mathrm{B}}^{7}\right)=\right.$ $2.6 \mathrm{~Hz}), 3.67-3.72$ br. $\mathrm{m}\left(1 \mathrm{H}, \mathrm{H}^{5},{ }^{3} J\left(\mathrm{H}^{5} \mathrm{H}_{\mathrm{A}}^{4}\right)=5.2 \mathrm{~Hz},{ }^{3} J\left(\mathrm{H}^{5}\right.\right.$ $\left.\left.\mathrm{H}^{4}{ }_{\mathrm{B}}\right)=1.7 \mathrm{~Hz}\right), 3.78 \mathrm{ddd}\left(1 \mathrm{H}, \mathrm{H}^{4}{ }_{\mathrm{A}},{ }^{2} J\left(\mathrm{H}^{4}{ }_{\mathrm{A}} \mathrm{H}^{4}{ }_{\mathrm{B}}\right)=-12.2 \mathrm{~Hz}\right.$, $\left.{ }^{4} J\left(\mathrm{H}_{\mathrm{A}}^{4} \quad \mathrm{H}^{6}\right)=-1.1 \mathrm{~Hz}\right), \quad 3.91$ ddd $\left(1 \mathrm{H}, \mathrm{H}_{\mathrm{A}}^{7},{ }^{2} J\left(\mathrm{H}_{\mathrm{A}}^{7}\right.\right.$ $\left.\left.\mathrm{H}^{7}{ }_{\mathrm{B}}\right)=-12.6 \mathrm{~Hz},{ }^{4} J\left(\mathrm{H}_{\mathrm{A}}^{7} \mathrm{H}^{5}\right)=-0.7 \mathrm{~Hz}\right), 4.06 \mathrm{dd}\left(1 \mathrm{H}, \mathrm{H}^{7}{ }_{\mathrm{B}}\right)$, $4.12 \mathrm{dd}\left(1 \mathrm{H}, \mathrm{H}_{\mathrm{B}}^{4}\right), 4.76 \mathrm{~s}\left(2 \mathrm{H}, 2 \mathrm{H}^{2}\right), 7.19-7.45 \mathrm{~m}(3 \mathrm{H}, 2,4-$ $\left.\mathrm{Cl}_{2} \mathrm{C}_{6} \mathrm{H}_{3}\right) .{ }^{13} \mathrm{C} \mathrm{NMR}\left(\mathrm{CDCl}_{3}\right), \delta: 54.11\left(\mathrm{C}^{6}\right), 65.07\left(\mathrm{C}^{7}\right), 66.34$ $\left(C^{4}\right), 71.51\left(C^{5}\right), 94.40\left(C^{2}\right), 127.77\left(C_{A r}\right), 129.05\left(C_{A r}\right)$, $130.13\left(\mathrm{C}_{\mathrm{Ar}}\right), 131.71\left(\mathrm{C}_{\mathrm{Ar}}\right), 133.37\left(\mathrm{C}_{\mathrm{Ar}}\right), 133.96\left(\mathrm{C}_{\mathrm{Ar}}\right), 137.11$ $\left(\mathrm{C}_{\mathrm{Ar}}\right)$. MS (EI): $m / z(\%)=294\left(\mathrm{M}^{+}, 46\right), 296\left(\mathrm{M}^{+}, 22\right)$.

2.2.25. 6-((2-Fluorophenyl)thio)-1,3-dioxepan-5-ol (29). Compound 29 was obtained from epoxide $2(0.2 \mathrm{~g}, 1.72 \mathrm{mmol})$ using a procedure similar to that used for the synthesis of compound 24.

Yield 93\% (0.39 g), colorless oil. ${ }^{1} \mathrm{H} \mathrm{NMR}\left(\mathrm{CDCl}_{3}\right), \delta$ : 3.07 br. $\mathrm{s}(1 \mathrm{H}, \mathrm{OH}), 3.15-3.19 \mathrm{~m}\left(1 \mathrm{H}, \mathrm{H}^{6},{ }^{3} J\left(\mathrm{H}^{6} \mathrm{H}^{5}\right)=5.4 \mathrm{~Hz}\right.$, $\left.{ }^{3} J\left(\mathrm{H}^{6} \mathrm{H}_{\mathrm{A}}^{7}\right)=6.3 \mathrm{~Hz},{ }^{3} J\left(\mathrm{H}^{6} \mathrm{H}_{\mathrm{B}}^{7}\right)=2.8 \mathrm{~Hz}\right), 3.63-3.67 \mathrm{~m}(1 \mathrm{H}$, $\left.\mathrm{H}^{5},{ }^{3} J\left(\mathrm{H}^{5} \mathrm{H}_{\mathrm{A}}^{4}\right)=5.7 \mathrm{~Hz},{ }^{3} J\left(\mathrm{H}^{5} \mathrm{H}_{\mathrm{B}}^{4}\right)=1.8 \mathrm{~Hz}\right), 3.74 \mathrm{ddd}(1 \mathrm{H}$, $\left.\mathrm{H}_{\mathrm{A}}^{4},{ }^{2} J\left(\mathrm{H}_{\mathrm{A}}^{4} \mathrm{H}_{\mathrm{B}}^{4}\right)=-12.0 \mathrm{~Hz}\right), 3.83 \mathrm{dd}\left(1 \mathrm{H}, \mathrm{H}_{\mathrm{A}}^{7}\right), 4.04 \mathrm{dd}$ $\left(1 \mathrm{H}, \mathrm{H}_{\mathrm{A}}^{7},{ }^{2} J\left(\mathrm{H}_{\mathrm{A}}^{7} \mathrm{H}_{\mathrm{B}}^{7}\right)=-12.5 \mathrm{~Hz}\right), 4.09 \mathrm{dd}\left(1 \mathrm{H}, \mathrm{H}_{\mathrm{B}}^{4}\right)$, 4.72 and $4.74\left(\mathrm{AB}, 2 \mathrm{H},{ }^{2} J\left(\mathrm{H}_{\mathrm{A}}^{2} \mathrm{H}_{\mathrm{B}}^{2}\right)=-4.4 \mathrm{~Hz}\right), 7.04-$ $7.51 \mathrm{~m}\left(4 \mathrm{H}, 2-\mathrm{FC}_{6} \mathrm{H}_{4}\right) .{ }^{13} \mathrm{C} \mathrm{NMR}\left(\mathrm{CDCl}_{3}\right), \delta: 54.61\left(\mathrm{C}^{6}\right.$, $\left.{ }^{4} J\left(\mathrm{FC}^{6}\right)=-1.2 \mathrm{~Hz}\right), 65.41\left(\mathrm{C}^{7}\right), 66.44\left(\mathrm{C}^{4}\right), 71.63\left(\mathrm{C}^{5}\right), 94.20$ $\left(\mathrm{C}^{2}\right), 116.20\left(\mathrm{C}_{\mathrm{Ar}},{ }^{2} J=-23.1 \mathrm{~Hz}\right), 120.02\left(\mathrm{C}_{\mathrm{Ar}},{ }^{2} J=-18.0 \mathrm{~Hz}\right)$, $124.75\left(\mathrm{C}_{\mathrm{Ar}},{ }^{3} \mathrm{~J}=3.8 \mathrm{~Hz}\right), 130.38\left(\mathrm{C}_{\mathrm{Ar}},{ }^{3} J=8.1 \mathrm{~Hz}\right), 135.49$ $\left(\mathrm{C}_{\mathrm{Ar}}\right), 162.59\left(\mathrm{C}_{\mathrm{Ar}},{ }^{1} J=246.0 \mathrm{~Hz}\right)$. MALDI-MS: $267[\mathrm{M}+\mathrm{Na}]^{+}$, $283[M+\mathrm{K}]^{+}$.

2.2.26. 6-((4-Fluorophenyl)thio)-1,3-dioxepan-5-ol (30). Compound 30 was obtained from epoxide $2(0.2 \mathrm{~g}, 1.72 \mathrm{mmol})$ using a procedure similar to that used for the synthesis of compound 24.

Yield $89 \%(0.37 \mathrm{~g})$, colorless crystals, m.p. $86-87^{\circ} \mathrm{C}$. ${ }^{1} \mathrm{H}$ NMR $\left(\mathrm{CDCl}_{3}\right), \delta: 2.91$ br. s $(1 \mathrm{H}, \mathrm{OH}), 3.08-3.12 \mathrm{~m}(1 \mathrm{H}$, $\mathrm{H}^{6},{ }^{3} J\left(\mathrm{H}^{6} \mathrm{H}^{5}\right)=5.9 \mathrm{~Hz},{ }^{3} J\left(\mathrm{H}^{6} \mathrm{H}_{\mathrm{A}}^{7}\right)=6.4 \mathrm{~Hz},{ }^{3} J\left(\mathrm{H}^{6} \mathrm{H}_{\mathrm{B}}^{7}\right)=$ $\left.2.8 \mathrm{~Hz},{ }^{4} J\left(\mathrm{H}^{6} \mathrm{H}_{\mathrm{A}}^{4}\right)=-0.8 \mathrm{~Hz}\right), 3.63-3.68$ br. $\mathrm{m}\left(1 \mathrm{H}, \mathrm{H}^{5},{ }^{3} J\left(\mathrm{H}^{5}\right.\right.$ $\left.\left.\mathrm{H}_{\mathrm{A}}^{4}\right)=6.0 \mathrm{~Hz},{ }^{3} J\left(\mathrm{H}^{5} \mathrm{H}_{\mathrm{B}}^{4}\right)=2.1 \mathrm{~Hz}\right), 3.74 \mathrm{ddd}\left(1 \mathrm{H}, \mathrm{H}_{\mathrm{A}}^{4}\right.$, $\left.{ }^{2} J\left(\mathrm{H}_{\mathrm{A}}^{4} \quad \mathrm{H}_{\mathrm{B}}^{4}\right)=-12.0 \mathrm{~Hz}\right), \quad 3.80$ dd $\left(1 \mathrm{H}, \mathrm{H}_{\mathrm{A}}^{7},{ }^{2} J\left(\mathrm{H}_{\mathrm{A}}^{7}\right.\right.$ $\left.\left.\mathrm{H}^{7}{ }_{\mathrm{B}}\right)=-12.5 \mathrm{~Hz}\right), 4.02 \mathrm{dd}\left(1 \mathrm{H}, \mathrm{H}^{7}{ }_{\mathrm{B}}\right), 4.07 \mathrm{dd}\left(1 \mathrm{H}, \mathrm{H}^{4}{ }_{\mathrm{B}}\right), 4.72$ and $4.74\left(\mathrm{AB}, 2 \mathrm{H},{ }^{2} J\left(\mathrm{H}^{2}{ }_{\mathrm{A}} \mathrm{H}^{2}{ }_{\mathrm{B}}\right)=-4.4 \mathrm{~Hz}\right), 9.97-7.48 \mathrm{~m}(4 \mathrm{H}$, $\left.4-\mathrm{FC}_{6} \mathrm{H}_{4}\right),{ }^{13} \mathrm{C} \mathrm{NMR}\left(\mathrm{CDCl}_{3}\right), \delta: 55.89\left(\mathrm{C}^{6}\right), 65.47\left(\mathrm{C}^{7}\right)$, $66.47\left(\mathrm{C}^{4}\right), 71.44\left(\mathrm{C}^{5}\right), 94.31\left(\mathrm{C}^{2}\right), 116.46\left(\mathrm{C}_{\mathrm{Ar}},{ }^{2} \mathrm{~J}=-21.9 \mathrm{~Hz}\right)$, $128.19\left(\mathrm{C}_{\mathrm{Ar}}\right), 135.14\left(\mathrm{C}_{\mathrm{Ar}},{ }^{3} J=8.2 \mathrm{~Hz}\right), 162.76\left(\mathrm{C}_{\mathrm{Ar}}\right.$, $\left.{ }^{1} J=248.5 \mathrm{~Hz}\right)$. MALDI-MS: $267[M+\mathrm{Na}]^{+}, 283[M+\mathrm{K}]^{+}$.

2.2.27. 6-((2-Bromophenyl)thio)-1,3-dioxepan-5-ol (31). Compound 31 was obtained from epoxide $2(0.2 \mathrm{~g}, 1.72 \mathrm{mmol})$ using a procedure similar to that used for the synthesis of compound 24.
Yield 78\% (0.41 g), colorless oil. ${ }^{1} \mathrm{H}$ NMR $\left(\mathrm{CDCl}_{3}\right), \delta$ : 3.01 br. $\mathrm{s}(1 \mathrm{H}, \mathrm{OH}), 3.29-3.33 \mathrm{~m}\left(1 \mathrm{H}, \mathrm{H}^{6},{ }^{3} J\left(\mathrm{H}^{6} \mathrm{H}^{5}\right)=5.5 \mathrm{~Hz}\right.$, $\left.{ }^{3} J\left(\mathrm{H}^{6} \mathrm{H}_{\mathrm{A}}^{7}\right)=5.7 \mathrm{~Hz},{ }^{3} J\left(\mathrm{H}^{6} \mathrm{H}_{\mathrm{B}}^{7}\right)=2.7 \mathrm{~Hz},{ }^{4} J\left(\mathrm{H}^{6} \mathrm{H}_{\mathrm{A}}^{4}\right)=-1.2 \mathrm{~Hz}\right)$, $3.72 \mathrm{dt}\left(1 \mathrm{H}, \mathrm{H}^{5},{ }^{3} J\left(\mathrm{H}^{5} \mathrm{H}^{4}{ }_{\mathrm{A}}\right)=5.3 \mathrm{~Hz},{ }^{3} J\left(\mathrm{H}^{5} \mathrm{H}^{4}{ }_{\mathrm{B}}\right)=1.5 \mathrm{~Hz}\right)$, $3.78 \mathrm{ddd}\left(1 \mathrm{H}, \mathrm{H}^{4}{ }_{\mathrm{A}},{ }^{2} J\left(\mathrm{H}^{4}{ }_{\mathrm{A}} \mathrm{H}^{4}{ }_{\mathrm{B}}\right)=-12.1 \mathrm{~Hz}\right), 3.93 \mathrm{dd}(1 \mathrm{H}$, $\left.\mathrm{H}_{\mathrm{A}}^{7},{ }^{2} J\left(\mathrm{H}_{\mathrm{A}}^{7} \mathrm{H}_{\mathrm{B}}^{7}\right)=-12.6 \mathrm{~Hz}\right), 4.14 \mathrm{dd}\left(1 \mathrm{H}, \mathrm{H}_{\mathrm{B}}^{7}\right), 4.14 \mathrm{dd}$ $\left(1 \mathrm{H}, \mathrm{H}_{\mathrm{B}}^{4}\right), 4.75$ and $4.76\left(\mathrm{AB}, 2 \mathrm{H},{ }^{2} J\left(\mathrm{H}^{2}{ }_{\mathrm{A}} \mathrm{H}_{\mathrm{B}}^{2}\right)=-4.6 \mathrm{~Hz}\right)$, 7.07-7.60 m (4H, 2- $\left.\mathrm{BrC}_{6} \mathrm{H}_{4}\right) .{ }^{13} \mathrm{C} \mathrm{NMR}\left(\mathrm{CDCl}_{3}\right), \delta: 54.17$ $\left(C^{6}\right), 65.21\left(C^{7}\right), 66.51\left(C^{4}\right), 71.51\left(C^{5}\right), 94.42\left(C^{2}\right), 126.70$ $\left(\mathrm{C}_{\mathrm{Ar}}\right), 128.12\left(\mathrm{C}_{\mathrm{Ar}}\right), 128.50\left(\mathrm{C}_{\mathrm{Ar}}\right), 132.03\left(\mathrm{C}_{\mathrm{Ar}}\right), 133.59\left(\mathrm{C}_{\mathrm{Ar}}\right)$, $135.14\left(\mathrm{C}_{\mathrm{Ar}}\right)$. MALDI-MS: $328[M+\mathrm{Na}]^{+}, 344[M+\mathrm{K}]^{+}$.

2.2.28. 6-((3-Bromophenyl)thio)-1,3-dioxepan-5-ol (32). Compound 32 was obtained from epoxide $2(0.2 \mathrm{~g}, 1.72 \mathrm{mmol})$ using a procedure similar to that used for the synthesis of compound 24.

Yield 89\% (0.47 g), colorless oil. ${ }^{1} \mathrm{H} \mathrm{NMR}\left(\mathrm{CDCl}_{3}\right), \delta: 2.96 \mathrm{br}$. $\mathrm{s}(1 \mathrm{H}, \mathrm{OH}), 3.22-3.26 \mathrm{~m}\left(1 \mathrm{H}, \mathrm{H}^{6},{ }^{3} J\left(\mathrm{H}^{6} \mathrm{H}^{5}\right)=5.4 \mathrm{~Hz},{ }^{3} J\left(\mathrm{H}^{6}\right.\right.$ $\left.\left.\mathrm{H}_{\mathrm{A}}^{7}\right)=5.8 \mathrm{~Hz},{ }^{3} J\left(\mathrm{H}^{6} \mathrm{H}_{\mathrm{B}}^{7}\right)=2.7 \mathrm{~Hz}\right), 3.69 \mathrm{dt}\left(1 \mathrm{H}, \mathrm{H}^{5},{ }^{3} J\left(\mathrm{H}^{5}\right.\right.$ $\left.\left.\mathrm{H}_{\mathrm{A}}^{4}\right)=5.5 \mathrm{~Hz},{ }^{3} J\left(\mathrm{H}^{5} \mathrm{H}_{\mathrm{B}}^{4}\right)=1.5 \mathrm{~Hz}\right), 3.76 \mathrm{dd}\left(1 \mathrm{H}, \mathrm{H}_{\mathrm{A}}^{4},{ }^{2} J\left(\mathrm{H}_{\mathrm{A}}^{4}\right.\right.$ $\left.\left.\mathrm{H}_{\mathrm{B}}^{4}\right)=-12.0 \mathrm{~Hz}\right), 3.84 \mathrm{dd}\left(1 \mathrm{H}, \mathrm{H}_{\mathrm{A}}^{7},{ }^{2} J\left(\mathrm{H}_{\mathrm{A}}^{7} \mathrm{H}_{\mathrm{B}}^{7}\right)=-12.5 \mathrm{~Hz}\right)$, $4.04 \mathrm{dd}\left(1 \mathrm{H}, \mathrm{H}_{\mathrm{B}}^{7}\right), 4.06 \mathrm{dd}\left(1 \mathrm{H}, \mathrm{H}_{\mathrm{B}}^{4}\right), 4.73$ and $4.74\left(1 \mathrm{H},{ }^{2} J\left(\mathrm{H}^{2}{ }_{\mathrm{A}}\right.\right.$ $\left.\left.\mathrm{H}_{\mathrm{B}}^{2}\right)=-4.6 \mathrm{~Hz}\right), \quad 7.13-7.56 \mathrm{~m} \quad\left(4 \mathrm{H}, 3-\mathrm{BrC}_{6} \mathrm{H}_{4}\right) .{ }^{13} \mathrm{C} \quad \mathrm{NMR}$ $\left(\mathrm{CDCl}_{3}\right), \delta: 54.75\left(\mathrm{C}^{6}\right), 65.22\left(\mathrm{C}^{7}\right), 66.39\left(\mathrm{C}^{4}\right), 71.50\left(\mathrm{C}^{5}\right), 94.27$ $\left(\mathrm{C}^{2}\right), 122.98\left(\mathrm{C}_{\mathrm{Ar}}\right), 129.86\left(\mathrm{C}_{\mathrm{Ar}}\right), 130.44\left(\mathrm{C}_{\mathrm{Ar}}\right), 130.53\left(\mathrm{C}_{\mathrm{Ar}}\right), 133.86$ $\left(\mathrm{C}_{\mathrm{Ar}}\right), 136.13\left(\mathrm{C}_{\mathrm{Ar}}\right)$. MALDI-MS: $328[M+\mathrm{Na}]^{+}, 344[M+\mathrm{K}]^{+}$.

2.2.29. 6-((4-Bromophenyl)thio)-1,3-dioxepan-5-ol (33). Compound 33 was obtained from epoxide $2(0.2 \mathrm{~g}, 1.72 \mathrm{mmol})$ using a procedure similar to that used for the synthesis of compound 24.

Yield $91 \%(0.48 \mathrm{~g})$, colorless crystals, m.p. $58-59^{\circ} \mathrm{C} .{ }^{1} \mathrm{H}$ $\operatorname{NMR}\left(\mathrm{CDCl}_{3}\right) \delta: 3.00$ br. d $\left(1 \mathrm{H}, \mathrm{OH},{ }^{3} J\left(\mathrm{OH} \mathrm{H} \mathrm{H}^{5}\right)=3.5 \mathrm{~Hz}\right)$, $3.18-3.23 \mathrm{~m}\left(1 \mathrm{H}, \mathrm{H}^{6},{ }^{3} J\left(\mathrm{H}^{6} \mathrm{H}^{5}\right)=5.5 \mathrm{~Hz},{ }^{3} J\left(\mathrm{H}^{6} \mathrm{H}_{\mathrm{A}}^{7}\right)=5.9 \mathrm{~Hz}\right.$, $\left.{ }^{3} J\left(\mathrm{H}^{6} \mathrm{H}_{\mathrm{B}}^{7}\right)=2.7 \mathrm{~Hz},{ }^{4} J\left(\mathrm{H}^{6} \mathrm{H}_{\mathrm{A}}^{4}\right)=-0.8 \mathrm{~Hz}\right), 3.72-3.77$ br. $\mathrm{m}$ $\left(1 \mathrm{H}, \mathrm{H}^{5},{ }^{3} J\left(\mathrm{H}^{5} \mathrm{H}_{\mathrm{A}}^{4}\right)=5.7 \mathrm{~Hz}\right), 3.74-3.78 \mathrm{~m}\left(1 \mathrm{H}, \mathrm{H}_{\mathrm{A}}^{4},{ }^{2} J\left(\mathrm{H}_{\mathrm{A}}^{4}\right.\right.$ $\left.\left.\mathrm{H}_{\mathrm{B}}^{4}\right)=-12.1 \mathrm{~Hz}\right), 3.83 \mathrm{dd}\left(1 \mathrm{H}, \mathrm{H}_{\mathrm{A}}^{7},{ }^{2} J\left(\mathrm{H}_{\mathrm{A}}^{7} \mathrm{H}_{\mathrm{B}}^{7}\right)=-12.5 \mathrm{~Hz}\right)$, $4.05 \mathrm{t}\left(1 \mathrm{H}, \mathrm{H}_{\mathrm{B}}^{7}\right), 4.06 \mathrm{t}\left(1 \mathrm{H}, \mathrm{H}_{\mathrm{B}}^{4}\right), 4.73$ and $4.75\left(\mathrm{AB}, 2 \mathrm{H},{ }^{2} J\right.$ $\left.\left(\mathrm{H}_{\mathrm{A}}^{2} \mathrm{H}_{\mathrm{B}}^{2}\right)=-4.6 \mathrm{~Hz}\right), 7.27-7.44 \mathrm{~m}\left(4 \mathrm{H}, 4-\mathrm{BrC}_{6} \mathrm{H}_{4}\right) .{ }^{13} \mathrm{C}$ $\operatorname{NMR}\left(\mathrm{CDCl}_{3}\right), \delta: 54.91\left(\mathrm{C}^{6}\right), 65.28\left(\mathrm{C}^{7}\right), 66.39\left(\mathrm{C}^{4}\right), 71.46\left(\mathrm{C}^{5}\right)$, $94.30\left(\mathrm{C}^{2}\right), 121.66\left(\mathrm{C}_{\mathrm{Ar}}\right), 132.36\left(\mathrm{C}_{\mathrm{Ar}}\right), 132.74\left(\mathrm{C}_{\mathrm{Ar}}\right), 133.30$ $\left(\mathrm{C}_{\mathrm{Ar}}\right)$. MALDI-MS: $328[\mathrm{M}+\mathrm{Na}]^{+}, 344[\mathrm{M}+\mathrm{K}]^{+}$.

2.2.30. The Separation of Racemic 6-(Phenylthio)-1,3dioxepan-5-ol 3 to Enantiomers by Fermentative Acylation with Use of Lipase PS. A mixture of vinyl acetate $(2.3 \mathrm{ml}$, $25 \mathrm{mmol})$ and lipase PS $(0.5 \mathrm{~g})$ immobilized on a diatomite was added to a solution of racemic 6-(phenylthio)-1,3dioxepan-5-ol $3(2.83 \mathrm{~g}, 12.52 \mathrm{mmol})$ in $30 \mathrm{ml}$ of toluene. The reaction mixture was stirred at $20^{\circ} \mathrm{C}$ for 48 hours. Then, lipase was filtered off, the solvent was evaporated under reduced pressure, and the product was separated by column chromatography (eluent petroleum ether-ethyl acetate, $7: 1$ ).

2.2.31. (5S,6S)-6-(Phenylthio)-1,3-dioxepan-5-ol (3-SS). Yield $45 \%(1.42 \mathrm{~g}),[\alpha]^{24}{ }_{\mathrm{D}}=1.7^{\circ}\left(c, 5 ; \mathrm{CH}_{2} \mathrm{Cl}_{2}\right)$, ee $>99 \%$. The spectral data completely correspond to the racemic sample. 
2.2.32. (5R,6R)-6-(Phenylthio)-1,3-dioxepan-5-yl Acetate (5$\boldsymbol{R} \boldsymbol{R})$. Yield $46 \%(1.55 \mathrm{~g}),[\alpha]_{\mathrm{D}}^{24}=-5.3^{\circ}\left(c, 5 ; \mathrm{CH}_{2} \mathrm{Cl}_{2}\right)$, ee $>99 \%$. The spectral data completely correspond to the racemic sample.

2.2.33. (5R,6R)-6-(Phenylthio)-1,3-dioxepan-5-ol (3-RR). $\mathrm{K}_{2} \mathrm{CO}_{3}(28 \mathrm{~g}, 9.3 \mathrm{mmol})$ was added to a solution of compound 5 -RR $(0.83 \mathrm{~g}, 3.1 \mathrm{mmol})$ in $20 \mathrm{ml}$ methanol. The mixture was stirred for 1 hour, then $\mathrm{K}_{2} \mathrm{CO}_{3}$ was filtered off, and the solvent was removed under vacuum. The product was purified by column chromatography (eluent petroleum ether-ethyl acetate, $1: 1)$. Yield $84 \%(0.59 \mathrm{~g}),[\alpha]_{\mathrm{D}}^{24}=-1.7^{\circ}$ $\left(c, 5 ; \mathrm{CH}_{2} \mathrm{Cl}_{2}\right.$ ), ee $>99 \%$. The spectral data completely correspond to the racemic sample.

2.2.34. (5S,6S)-6-((2-Fluorophenyl)thio)-1,3-dioxepan-5-ol (29-SS). This compound was obtained from racemic alcohol 29 ( $1.00 \mathrm{~g}, 4.09 \mathrm{mmol})$ using a procedure similar to that used for the synthesis of compound 3-SS. Yield 45\% (0.45 g), colorless oil, $[\alpha]_{\mathrm{D}}^{24}=1.2^{\circ}\left(c, 5 ; \mathrm{CH}_{2} \mathrm{Cl}_{2}\right)$, ee $>99 \%$. The spectral data completely correspond to the racemic sample.

2.2.35. (5R,6R)-6-((2-Fluorophenyl)thio)-1,3-dioxepan-5-yl Acetate (34). This compound was obtained from racemic alcohol $29(1.00 \mathrm{~g}, 4.09 \mathrm{mmol})$ using a procedure similar to that used for the synthesis of compound 5-RR.

Yield $46 \%(0.54 \mathrm{~g})$, colorless crystals, m.p. $51-52^{\circ} \mathrm{C}$, $[\alpha]^{24}{ }_{\mathrm{D}}=-0.4^{\circ}\left(c, 5 ; \mathrm{CH}_{2} \mathrm{Cl}_{2}\right)$, ee $>99 \% .{ }^{1} \mathrm{H} \mathrm{NMR}\left(\mathrm{CDCl}_{3}\right)$, $\delta$ : $2.05 \mathrm{~s}\left(3 \mathrm{H}, \mathrm{CH}_{3}\right), 3.34-3.38 \mathrm{~m}\left(1 \mathrm{H}, \mathrm{H}^{6},{ }^{3} J\left(\mathrm{H}^{6} \mathrm{H}^{5}\right)=\right.$ $\left.5.5 \mathrm{~Hz},{ }^{3} J\left(\mathrm{H}^{6} \mathrm{H}_{\mathrm{A}}^{7}\right)=6.5 \mathrm{~Hz},{ }^{3} J\left(\mathrm{H}^{6} \mathrm{H}^{7}{ }_{\mathrm{B}}\right)=2.1 \mathrm{~Hz}\right), 3.87 \mathrm{dd}$ $\left(1 \mathrm{H}, \mathrm{H}_{\mathrm{A}}^{7},{ }^{2} J\left(\mathrm{H}_{\mathrm{A}}^{7} \mathrm{H}_{\mathrm{B}}^{7}\right)=-12.3 \mathrm{~Hz}\right), 3.89 \mathrm{dd}\left(1 \mathrm{H}, \mathrm{H}^{4}{ }_{\mathrm{A}},{ }^{2} J\right.$ $\left.\left(\mathrm{H}^{4}{ }_{\mathrm{A}} \mathrm{H}^{4}{ }_{\mathrm{B}}\right)=-12.7 \mathrm{~Hz},{ }^{3} J\left(\mathrm{H}^{4}{ }_{\mathrm{A}} \mathrm{H}^{5}\right)=5.6 \mathrm{~Hz}\right), 4.08 \mathrm{dd}(1 \mathrm{H}$, $\left.\mathrm{H}^{4}{ }_{\mathrm{B}},{ }^{3} J\left(\mathrm{H}^{4}{ }_{\mathrm{B}} \mathrm{H}^{5}\right)=2.1 \mathrm{~Hz}\right), 4.15 \mathrm{ddd}\left(1 \mathrm{H}, \mathrm{H}^{7}{ }_{\mathrm{B}}\right), 4.75$ and $4.80\left(\mathrm{AB}, 2 \mathrm{H}, 2 \mathrm{H}^{2},{ }^{2} \mathrm{~J}\left(\mathrm{H}_{\mathrm{A}}^{2} \mathrm{H}^{2}{ }_{\mathrm{B}}\right)=-4.4 \mathrm{~Hz}\right), 4.87 \mathrm{dt}(1 \mathrm{H}$, $\left.\mathrm{H}^{5}\right), 7.08-7.54 \mathrm{~m}\left(4 \mathrm{H}, 2-\mathrm{FC}_{6} \mathrm{H}_{4}\right) .{ }^{13} \mathrm{C} \mathrm{NMR}\left(\mathrm{CDCl}_{3}\right), \delta$ : $21.15\left(\mathrm{CH}_{3}\right), 51.89\left(\mathrm{C}^{6}\right), 65.23\left(\mathrm{C}^{7(4)}\right), 65.34\left(\mathrm{C}^{4(7)}\right), 73.82$ $\left(\mathrm{C}^{5}\right), 94.49\left(\mathrm{C}^{2}\right), 116.18\left(\mathrm{C}_{\mathrm{Ar}},{ }^{2} J=-23.1 \mathrm{~Hz}\right), 120.09\left(\mathrm{C}_{\mathrm{Ar}}\right.$, $\left.{ }^{2} J=-17.8 \mathrm{~Hz}\right), 124.76\left(\mathrm{C}_{\mathrm{Ar}},{ }^{3} J=3.7 \mathrm{~Hz}\right), 130.49\left(\mathrm{C}_{\mathrm{Ar}}\right.$, $\left.{ }^{3} J=8.0 \mathrm{~Hz}\right), 135.60\left(\mathrm{C}_{\mathrm{Ar}}\right), 162.69\left(\mathrm{C}_{\mathrm{Ar}},{ }^{1} J=246.4 \mathrm{~Hz}\right)$, 170.19 (CO). MALDI-MS: $309[M+\mathrm{Na}]^{+}, 328[M+\mathrm{K}]^{+}$.

2.2.36. (5R,6R)-6-((2-Fluorophenyl)thio)-1,3-dioxepan-5-ol $(29-\boldsymbol{R})$. This compound was obtained from acetate 34 $(0.5 \mathrm{~g}, 1.75 \mathrm{mmol})$ using a procedure similar to that used for the synthesis of compound 3-RR. Yield 93\% (0.40 g), colorless oil, $[\alpha]_{\mathrm{D}}^{24}=-1.2^{\circ}\left(c, 5 ; \mathrm{CH}_{2} \mathrm{Cl}_{2}\right)$, ee $>99 \%$. The spectral data completely correspond to the racemic sample.

2.2.37. (5S,6S)-6-((2-Bromophenyl)thio)-1,3-dioxepan-5-ol (31-SS). This compound was obtained from racemic alcohol 31 ( $1.0 \mathrm{~g}, 3.28 \mathrm{mmol})$ using a procedure similar to that used for the synthesis of compound 3-SS. Yield $41 \%(0.41 \mathrm{~g})$, colorless oil, $[\alpha]_{D}^{24}=1.0^{\circ}\left(c, 5 ; \mathrm{CH}_{2} \mathrm{Cl}_{2}\right)$, ee $>99 \%$. The spectral data completely correspond to the racemic sample.
2.2.38. (5R,6R)-6-((2-Bromophenyl)thio)-1,3-dioxepan-5-yl Acetate (35). This compound was obtained from racemic alcohol 31 ( $1 \mathrm{~g}, 3.28 \mathrm{mmol}$ ) using a procedure similar to that used for the synthesis of compound 5-RR.

Yield $45 \%(0.51 \mathrm{~g})$, colorless oil, $[\alpha]_{\mathrm{D}}^{24}=-0.2^{\circ}(c, 5$; $\left.\mathrm{CH}_{2} \mathrm{Cl}_{2}\right)$, ee $>99 \% .{ }^{1} \mathrm{H} \mathrm{NMR}\left(\mathrm{CDCl}_{3}\right), \delta: 2.08 \mathrm{~s}\left(3 \mathrm{H}, \mathrm{CH}_{3}\right)$, $3.43-3.48 \mathrm{~m}\left(1 \mathrm{H}, \mathrm{H}^{6},{ }^{3} J\left(\mathrm{H}^{6} \mathrm{H}^{5}\right)=4.6 \mathrm{~Hz},{ }^{3} J\left(\mathrm{H}^{6} \mathrm{H}^{7} \mathrm{~A}\right)=5.3 \mathrm{~Hz}\right.$, $\left.{ }^{3} J\left(\mathrm{H}^{6} \mathrm{H}_{\mathrm{B}}^{7}\right)=2.2 \mathrm{~Hz},{ }^{4} J\left(\mathrm{H}^{6} \mathrm{H}_{\mathrm{A}}^{4}\right)=-1.2 \mathrm{~Hz}\right), 3.92 \mathrm{ddd}\left(1 \mathrm{H}, \mathrm{H}^{4}\right.$, $\left.{ }^{2} J\left(\mathrm{H}^{4}{ }_{\mathrm{A}} \mathrm{H}^{4}{ }_{\mathrm{B}}\right)=-12.8 \mathrm{~Hz},{ }^{3} J\left(\mathrm{H}^{4}{ }_{\mathrm{A}} \mathrm{H}^{5}\right)=4.7 \mathrm{~Hz}\right), 3.96 \mathrm{ddd}(1 \mathrm{H}$, $\left.\mathrm{H}_{\mathrm{A}}^{7},{ }^{2} J\left(\mathrm{H}_{\mathrm{A}}^{7} \mathrm{H}_{\mathrm{B}}^{7}\right)=-12.3 \mathrm{~Hz},{ }^{4} J\left(\mathrm{H}_{\mathrm{A}}^{7} \mathrm{H}^{5}\right)=-0.8 \mathrm{~Hz}\right), 4.13 \mathrm{dd}$ $\left(1 \mathrm{H}, \mathrm{H}_{\mathrm{B}}^{4},{ }^{3} J\left(\mathrm{H}_{\mathrm{B}}^{4} \mathrm{H}^{5}\right)=2.0 \mathrm{~Hz}\right), 4.18 \mathrm{dd}\left(1 \mathrm{H}, \mathrm{H}^{7}{ }_{\mathrm{B}}\right), 4.77$ and $4.82\left(\mathrm{AB}, 2 \mathrm{H}, 2 \mathrm{H}^{2},{ }^{2} \mathrm{~J}\left(\mathrm{H}_{\mathrm{A}}^{2} \mathrm{H}_{\mathrm{B}}^{2}\right)=-4.4 \mathrm{~Hz}\right), 4.92 \mathrm{dt}\left(1 \mathrm{H}, \mathrm{H}^{5}\right)$, 7.09-7.60 m (4H, 2- $\left.\mathrm{BrC}_{6} \mathrm{H}_{4}\right) .{ }^{13} \mathrm{C} \mathrm{NMR}\left(\mathrm{CDCl}_{3}\right), \delta: 21.13$ $\left(\mathrm{CH}_{3}\right), 51.72\left(\mathrm{C}^{6}\right), 64.87\left(\mathrm{C}^{7(4)}\right), 65.47\left(\mathrm{C}^{4(7)}\right), 73.65\left(\mathrm{C}^{5}\right), 94.47$ $\left(\mathrm{C}^{2}\right), 126.64\left(\mathrm{C}_{\mathrm{Ar}}\right), 128.05\left(\mathrm{C}_{\mathrm{Ar}}\right), 128.55\left(\mathrm{C}_{\mathrm{Ar}}\right), 132.40\left(\mathrm{C}_{\mathrm{Ar}}\right)$, $133.49\left(\mathrm{C}_{\mathrm{Ar}}\right), 134.97\left(\mathrm{C}_{\mathrm{Ar}}\right), 170.10$ (CO). MALDI-MS: 370 $[M+\mathrm{Na}]^{+}, 386[M+\mathrm{K}]^{+}$.

2.2.39. (5R,6R)-6-((2-Bromophenyl)thio)-1,3-dioxepan-5-ol (31-RR). This compound was obtained from acetate 35 $(0.5 \mathrm{~g}, 1.44 \mathrm{mmol})$ using a procedure similar to that used for the synthesis of compound 3-RR. Yield 98\% (0.43 g), colorless oil, $[\alpha]_{\mathrm{D}}^{24}=-1.0^{\circ}\left(c, 5 ; \mathrm{CH}_{2} \mathrm{Cl}_{2}\right)$, ee $>99 \%$. The spectral data completely correspond to the racemic sample.

2.2.40. (5S,6S)-6-((3-Bromophenyl)thio)-1,3-dioxepan-5-ol (32-SS). This compound was obtained from racemic alcohol $32(1.0 \mathrm{~g}, 3.28 \mathrm{mmol})$ using a procedure similar to that used for the synthesis of compound 3-SS. Yield 40\% (0.40 g), colorless crystals, m.p. $69-70^{\circ} \mathrm{C},[\alpha]^{24}{ }_{\mathrm{D}}=1.2^{\circ}\left(c, 5 ; \mathrm{CH}_{2} \mathrm{Cl}_{2}\right)$, ee $>99 \%$. The spectral data completely correspond to the racemic sample. HPLC retention time $109.9 \mathrm{~min}$ (chiral stationary phase).

2.2.41. (5R,6R)-6-((3-Bromophenyl)thio)-1,3-dioxepan-5-yl Acetate (36). This compound was obtained from racemic alcohol $32(1.0 \mathrm{~g}, 3.28 \mathrm{mmol})$ using a procedure similar to that used for the synthesis of compound 5-RR.

Yield $40 \%(0.45 \mathrm{~g})$, colorless oil, $[\alpha]_{\mathrm{D}}^{24}=-0.1^{\circ}(c, 5$; $\left.\mathrm{CH}_{2} \mathrm{Cl}_{2}\right)$, ee $>99 \% .{ }^{1} \mathrm{H} \mathrm{NMR}\left(\mathrm{CDCl}_{3}\right), \delta: 2.09 \mathrm{~s}\left(3 \mathrm{H}, \mathrm{CH}_{3}\right)$, $3.45 \mathrm{dt}\left(1 \mathrm{H}, \mathrm{H}^{6},{ }^{3} J\left(\mathrm{H}^{6} \mathrm{H}^{5}\right)=5.4 \mathrm{~Hz},{ }^{3} J\left(\mathrm{H}^{6} \mathrm{H}_{\mathrm{A}}^{7}\right)=6.2 \mathrm{~Hz}\right.$, $\left.{ }^{3} J\left(\mathrm{H}^{6} \mathrm{H}_{\mathrm{B}}^{7}\right)=2.3 \mathrm{~Hz}\right), 3.84$ dd $\left(1 \mathrm{H}, \mathrm{H}_{\mathrm{A}}^{7},{ }^{2} J\left(\mathrm{H}_{\mathrm{A}}^{7} \mathrm{H}_{\mathrm{B}}^{7}\right)\right.$ $=-12.3 \mathrm{~Hz}), 3.87 \mathrm{dd}\left(1 \mathrm{H}, \mathrm{H}_{\mathrm{A}}^{4},{ }^{2} J\left(\mathrm{H}_{\mathrm{A}}^{4} \mathrm{H}_{\mathrm{B}}^{4}\right)=-12.3 \mathrm{~Hz},{ }^{3} J\right.$ $\left.\left(\mathrm{H}_{\mathrm{A}}^{4} \mathrm{H}^{5}\right)=5.4 \mathrm{~Hz}\right), 4.03 \mathrm{dd}\left(1 \mathrm{H}, \mathrm{H}_{\mathrm{B}}^{4},{ }^{3} J\left(\mathrm{H}_{\mathrm{B}}^{4} \mathrm{H}^{5}\right)=2.3 \mathrm{~Hz}\right)$, 4.13 dd $\left(1 \mathrm{H}, \mathrm{H}_{\mathrm{B}}^{7}\right), 4.74$ and $4.80\left(\mathrm{AB}, 2 \mathrm{H}, 2 \mathrm{H}^{2},{ }^{2} J\left(\mathrm{H}_{\mathrm{A}}^{2}\right.\right.$ $\left.\left.\mathrm{H}^{2}{ }_{\mathrm{B}}\right)=-4.6 \mathrm{~Hz}\right), 4.92 \mathrm{dt}\left(1 \mathrm{H}, \mathrm{H}^{5}\right), 7.15-7.63 \mathrm{~m}(4 \mathrm{H}$, 3- $\left.\mathrm{BrC}_{6} \mathrm{H}_{4}\right) .{ }^{13} \mathrm{C} \mathrm{NMR}\left(\mathrm{CDCl}_{3}\right), \delta: 21.07\left(\mathrm{CH}_{3}\right), 52.06\left(\mathrm{C}^{6}\right)$, $65.08\left(\mathrm{C}^{7(4)}\right), 65.40\left(\mathrm{C}^{4(7)}\right), 73.65\left(\mathrm{C}^{5}\right), 94.38\left(\mathrm{C}^{2}\right), 122.84$ $\left(\mathrm{C}_{\mathrm{Ar}}\right), 129.85\left(\mathrm{C}_{\mathrm{Ar}}\right), 130.37\left(\mathrm{C}_{\mathrm{Ar}}\right), 130.42\left(\mathrm{C}_{\mathrm{Ar}}\right), 133.81$ $\left(\mathrm{C}_{\mathrm{Ar}}\right), 136.07\left(\mathrm{C}_{\mathrm{Ar}}\right), 170.04(\mathrm{CO})$. MALDI-MS: $370[\mathrm{M}$ $+\mathrm{Na}]^{+}, 386[M+\mathrm{K}]^{+}$.

2.2.42. (5R,6R)-6-((3-Bromophenyl)thio)-1,3-dioxepan-5-ol (32-RR). This compound was obtained from acetate 36 $(0.5 \mathrm{~g}, 1.44 \mathrm{mmol})$ using a procedure similar to that used for the synthesis of compound 3-RR. Yield $98 \%(0.43 \mathrm{~g})$, colorless crystals, m.p. $69-70^{\circ} \mathrm{C},[\alpha]_{\mathrm{D}}^{24}=-1.2^{\circ}\left(c, 5 ; \mathrm{CH}_{2} \mathrm{Cl}_{2}\right)$, 
ee $>99 \%$. The spectral data completely correspond to the racemic sample. HPLC retention time $116.6 \mathrm{~min}$ (chiral stationary phase).

2.2.43. (5S,6S)-6-((4-Bromophenyl)thio)-1,3-dioxepan-5-ol (33-SS). This compound was obtained from racemic alcohol $33(1.0 \mathrm{~g}, 3.28 \mathrm{mmol})$ using a procedure similar to that used for the synthesis of compound 3-SS. Yield 39\% (0.39 g), colorless crystals, m.p. $68-69^{\circ} \mathrm{C},[\alpha]^{24}{ }_{\mathrm{D}}=1.0^{\circ}\left(c, 5 ; \mathrm{CH}_{2} \mathrm{Cl}_{2}\right)$, ee $>99 \%$. The spectral data completely correspond to the racemic sample.

2.2.44. (5R,6R)-6-((4-Bromophenyl)thio)-1,3-dioxepan-5-yl Acetate (37). This compound was obtained from racemic alcohol $33(1.0 \mathrm{~g}, 3.28 \mathrm{mmol})$ using a procedure similar to that used for the synthesis of compound 5-RR. Yield $40 \%$ $(0.46 \mathrm{~g})$, colorless oil, $[\alpha]_{\mathrm{D}}^{24}=-0.9^{\circ}\left(c, 5 ; \mathrm{CH}_{2} \mathrm{Cl}_{2}\right)$, ee $>99 \%$. ${ }^{1} \mathrm{H}$ NMR $\left(\mathrm{CDCl}_{3}\right), \delta: 2.09 \mathrm{~s}\left(3 \mathrm{H}, \mathrm{CH}_{3}\right), 3.32 \mathrm{dt}\left(1 \mathrm{H}, \mathrm{H}^{6}\right.$, ${ }^{3} J\left(\mathrm{H}^{6} \mathrm{H}^{5}\right)=5.4 \mathrm{~Hz},{ }^{3} J\left(\mathrm{H}^{6} \quad \mathrm{H}_{\mathrm{A}}^{7}\right)=6.1 \mathrm{~Hz},{ }^{3} J\left(\mathrm{H}^{6} \mathrm{H}_{\mathrm{B}}^{7}\right)=$ $2.4 \mathrm{~Hz}), 3.82 \mathrm{dd}\left(1 \mathrm{H}, \mathrm{H}_{\mathrm{A}}^{7},{ }^{2} J\left(\mathrm{H}^{7}{ }_{\mathrm{A}} \mathrm{H}_{\mathrm{B}}^{7}\right)=-12.3 \mathrm{~Hz}\right), 3.86 \mathrm{dd}$ $\left(1 \mathrm{H}, \mathrm{H}_{\mathrm{A}}^{4},{ }^{2} J\left(\mathrm{H}_{\mathrm{A}}^{4} \mathrm{H}_{\mathrm{B}}^{4}\right)=-12.5 \mathrm{~Hz},{ }^{3} J\left(\mathrm{H}_{\mathrm{A}}^{4} \mathrm{H}^{5}\right)=5.3 \mathrm{~Hz}\right)$, $4.03 \mathrm{dd}\left(1 \mathrm{H}, \mathrm{H}_{\mathrm{B}}^{4},{ }^{3} J\left(\mathrm{H}^{4}{ }_{\mathrm{B}} \mathrm{H}^{5}\right)=2.3 \mathrm{~Hz}\right), 4.13 \mathrm{dd}\left(1 \mathrm{H}, \mathrm{H}^{7}{ }_{\mathrm{B}}\right)$, 4.73 and $4.80\left(\mathrm{AB}, 2 \mathrm{H}, 2 \mathrm{H}^{2},{ }^{2} J\left(\mathrm{H}^{2}{ }_{\mathrm{A}} \mathrm{H}^{2}{ }_{\mathrm{B}}\right)=-4.6 \mathrm{~Hz}\right), 4.91 \mathrm{dt}$ $\left(1 \mathrm{H}, \mathrm{H}^{5}\right), 7.32-7.44 \mathrm{~m}\left(4 \mathrm{H}, 4-\mathrm{BrC}_{6} \mathrm{H}_{4}\right) .{ }^{13} \mathrm{C} \mathrm{NMR}\left(\mathrm{CDCl}_{3}\right)$, $\delta: 21.13\left(\mathrm{CH}_{3}\right), 52.26\left(\mathrm{C}^{6}\right), 65.23\left(\mathrm{C}^{7(4)}\right), 65.45\left(\mathrm{C}^{4(7)}\right), 73.66$ $\left(\mathrm{C}^{5}\right), 94.46\left(\mathrm{C}^{2}\right), 121.75\left(\mathrm{C}_{\mathrm{Ar}}\right), 132.27\left(\mathrm{C}_{\mathrm{Ar}}\right), 132.68\left(\mathrm{C}_{\mathrm{Ar}}\right)$, $133.48\left(\mathrm{C}_{\mathrm{Ar}}\right), 170.11(\mathrm{CO})$. MALDI-MS: $370[\mathrm{M}+\mathrm{Na}]^{+}, 386$ $[M+\mathrm{K}]^{+}$.

2.2.45. (5R,6R)-6-((4-Bromophenyl)thio)-1,3-dioxepan-5-ol (33-RR). This compound was obtained from racemic acetate $37(0.5 \mathrm{~g}, 1.44 \mathrm{mmol})$ using a procedure similar to that used for the synthesis of compound 3-RR. Yield $91 \%$ $(0.40 \mathrm{~g})$, colorless crystals, m.p. $68-69^{\circ} \mathrm{C},[\alpha]^{24}{ }_{\mathrm{D}}=-1.0^{\circ}(c, 5$; $\mathrm{CH}_{2} \mathrm{Cl}_{2}$ ), ee $>99 \%$. The spectral data completely correspond to the racemic sample.

\subsection{Crystal Structure Determinations}

The X-ray diffraction data for the crystals of 6,7 , and 9 were collected on a Smart Apex II automatic diffractometer using graphite monochromated radiation $\mathrm{MoK}_{\alpha}(\lambda$ 0.71073). The structures were solved by a direct method using the SHELXS [21] program and refined by full-matrix least-squares using SHELXL2014 [21] program. All the nonhydrogen atoms were refined with anisotropic atomic displacement parameters. $\mathrm{H}(\mathrm{C})$ atoms were constrained as riding atoms, with the $\mathrm{C}-\mathrm{H}$ set to $0.95 \AA$. All calculations were performed using WinGX [22] and APEX [23] programs. Crystallographic data (excluding structure factors) for the structures 6, 7, and 9 reported in this paper have been deposited with the Cambridge Crystallographic Data Centre as supplementary publication, the corresponding CCDC numbers are given in Table 1. These data can be obtained free of charge from The Cambridge Crystallographic Data Centre via http://www. ccdc.cam.ac.uk/data_request/cif.

\subsection{Biological Studies}

2.4.1. Antifungal Activity Studies. The antifungal activity has been tested against 4 clinical strains, C. albicans, A. fumigatus, E. floccosum, and Mucor pusilos, that were obtained from a collection of typical and clinical cultures of the mycological laboratory of the Kazan Research Institute of Epidemiology and Microbiology.

The fungal activity was evaluated in vitro using a minimum inhibitory concentration (MIC) test according to NCCLS guidelines. The tested substances were dissolved in Sabouraud medium to obtain the solutions with concentrations two times higher than the final ones. Then, $1 \mathrm{ml}$ of each solution and $1 \mathrm{ml}$ of fungal spore suspension (concentration of $10^{6}$ fungal spores per $1 \mathrm{ml}$ ) were added to the test tube. The final concentrations of the tested compounds were $(\mathrm{mg} / \mathrm{ml}): 10 ; 5 ; 2.5 ; 1.2 ; 0.6 ; 0.3 ; 0.15 ; 0.07 ; 0.03 ; 0.015$; and 0.007 . The fungal spore solutions or vegetative cells were obtained from a viable 48-hour old yeast-like fungal culture and 6-day old mycelial fungi. The test tubes were incubated at $28^{\circ} \mathrm{C}-30^{\circ} \mathrm{C}$ for 9 days. The culture growth was followed with a photoelectric colorimeter at $530 \mathrm{~nm}$ using pure medium as a blank control.

2.4.2. Cytotoxicity Studies. Human skin fibroblasts (HSFs) were isolated from the skin explant according to the conventional protocol [24]. HSFs cells were cultured in the minimum essential medium Eagle (a-MEM) supplemented with $10 \%$ fetal bovine serum, $2 \mathrm{mM} \mathrm{L}$-glutamine, $100 \mu \mathrm{g} / \mathrm{mL}$ streptomycin, and $100 \mathrm{U} / \mathrm{mL}$ penicillin under standard conditions $\left(37^{\circ} \mathrm{C}, 5 \% \mathrm{CO}_{2}\right.$ atmosphere). Adhered cells were collected from the culture flask by detaching them with trypsin-EDTA solution. Suspended cells were by centrifugation at $200 \mathrm{~g}$ in PBS. Cytotoxic concentrations $\left(\mathrm{IC}_{50}\right)$ of compounds were determined with the use of MTT assay. Cells were preseeded in a 96-well plate at the density of $1,000-2,000$ cells per well and then incubated with aqueous solutions of the tested compounds for 3 days under standard conditions. Culture medium in the plate was then replaced by the fresh one supplemented with $0.5 \mathrm{mg} / \mathrm{mL}$ MTT and additionally kept for $4 \mathrm{~h}$ to allow for reduction of MTT into colored product (formazan) by metabolically active cells. Optical absorbance of produced formazan, proportional to viable cell number, was registered on an Infinite 200 PRO analyzer at $550 \mathrm{~nm}$.

\section{Results and Discussion}

In continuation of our research on reactions of 3,5,8-trioxabicyclo[5.1.0] octanes with nucleophiles and antimycotic properties of the obtained products [13], in this work we have carried out the thiolysis reaction of epoxide 2 by thiophenol followed by functionalization of the resulting $\beta$-hydroxysulfide 3 (Scheme 1). The functionalization was performed by oxidation of the sulfur atom and/or acylation of the hydroxyl group (compounds 4-6). Our attempts to synthesize compound 4 from acetate $\mathbf{6}$ by removing the acetate group with potassium carbonate led to formation of 
TABle 1: Parameters of crystals of compounds 6, 7, and 9 and conditions of X-ray diffraction experiments.

\begin{tabular}{|c|c|c|c|}
\hline Compound reference & 6 & 7 & 9 \\
\hline Temperature (K) & $293(2)$ & $293(2)$ & $293(2)$ \\
\hline Chemical formula & $\mathrm{C}_{13} \mathrm{H}_{16} \mathrm{O}_{6} \mathrm{~S}$ & $\mathrm{C}_{11} \mathrm{H}_{12} \mathrm{O}_{4} \mathrm{~S}$ & $\mathrm{C}_{11} \mathrm{H}_{14} \mathrm{O}_{3} \mathrm{~S}$ \\
\hline Formula mass & 300.32 & 240.27 & 226.28 \\
\hline Crystal system & Triclinic & Monoclinic & Monoclinic \\
\hline$A(\AA)$ & $8.2534(12)$ & $12.770(5)$ & $17.337(6)$ \\
\hline$b(\AA)$ & $9.2870(14)$ & $7.578(3)$ & $4.8550(16)$ \\
\hline$c(\AA)$ & $10.2792(15)$ & $11.525(5)$ & $13.336(4)$ \\
\hline$\alpha\left(^{\circ}\right)$ & $110.116(2)$ & 90 & 90 \\
\hline$\beta\left(^{\circ}\right)$ & $97.389(2)$ & $100.639(5)$ & $96.440(3)$ \\
\hline$\gamma\left({ }^{\circ}\right)$ & $105.359(2)$ & 90 & 90 \\
\hline Unit cell volume $\left(\AA^{3}\right)$ & $692.09(18)$ & $1096.1(8)$ & $1115.4(6)$ \\
\hline Space group & $\mathrm{P}-1$ & $\mathrm{P} 21 / \mathrm{c}$ & $\mathrm{P} 21 / \mathrm{c}$ \\
\hline No. of formula units per unit cell $(Z)$ & 2 & 4 & 4 \\
\hline No. of reflections measured & 3436 & 6931 & 8394 \\
\hline No. of independent reflections & 1883 & 1764 & 2414 \\
\hline$R_{\text {int }}$ & 0.109 & 0.030 & 0.031 \\
\hline Final $R_{1}$ values $(I>2 \sigma(I))$ & 0.0664 & 0.0351 & 0.0546 \\
\hline Final $w R\left(F^{2}\right)$ values $(I>2 \sigma(I))$ & 0.1807 & 0.0902 & 0.1462 \\
\hline Final $R_{1}$ values (all data) & 0.0704 & 0.0426 & 0.0670 \\
\hline Final $w R\left(F^{2}\right)$ values (all data) & 0.1858 & 0.0949 & 0.1568 \\
\hline CCDC numbers & 1513085 & 1513086 & 1513087 \\
\hline
\end{tabular}

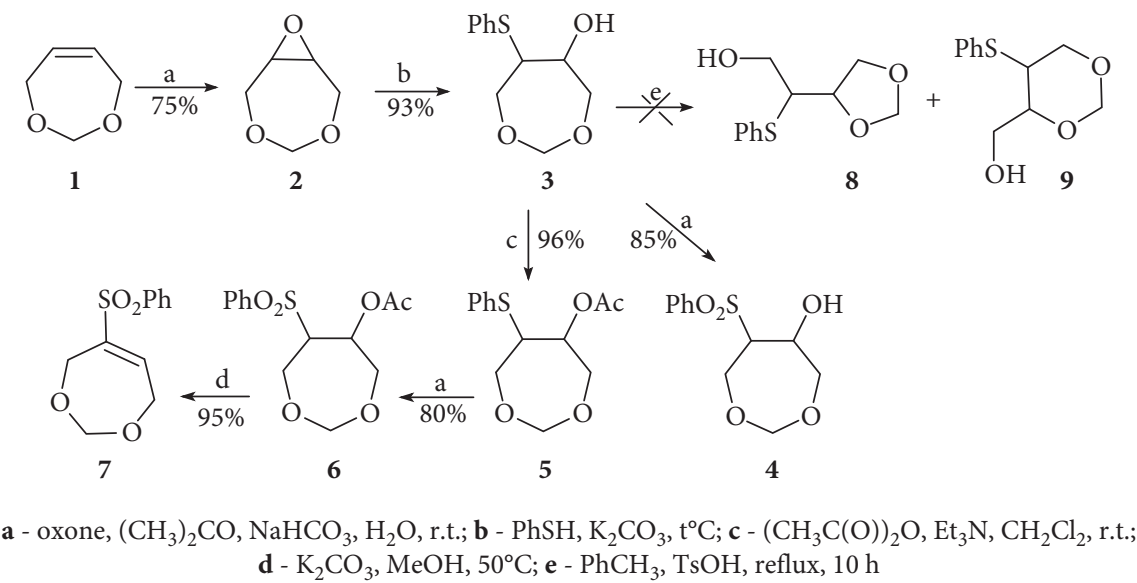

Scheme 1: Synthesis of hydroxysulfide of 1,3-dioxepane series and its further functionalization.

compound 7. This result suggested that the presence of the electron-withdrawing $\mathrm{PhSO}_{2}$ fragment increased the acidity of methine proton which led to its elimination even under weak alkali treatment. Our further attempts to obtain the corresponding 1,3-dioxolane 8 and 1,3-dioxane 9 with the reduced cycle size via acidic isomerization of compound 3 were not successful.

In order to obtain compounds $\mathbf{8}$ and $\mathbf{9}$, we then tried alternative synthetic routes depicted in Scheme 2. The intermediate $\mathbf{1 2}$ was obtained from diol $\mathbf{1 0}$ via its oxidation with oxone followed by thiolysis of the resulting epoxide $\mathbf{1 1}$ with thiophenol in hot water in the presence of DABCO. Further condensation of triol $\mathbf{1 2}$ with paraformaldehyde resulted in an inseparable mixture of compounds $\mathbf{3}, \mathbf{8}$, and $\mathbf{9}$, as well as the products of their reaction with paraformaldehyde. ${ }^{1} \mathrm{H}$ NMR spectral data demonstrated that initial 1,3-dioxepane 3 was the major component of the reaction mixture in all cases. Similar results were described in a previous paper [25]. The condensation reaction of butane-1,2,4-triol with paraformaldehyde under similar conditions led to a mixture of five- and six-membered rings, where six-membered ring structure was the product of both kinetic and thermodynamic control $[26,27]$. It was clear that the presence of thiophenyl group in triol $\mathbf{1 2}$ significantly changed the ratio of the obtained isomers. In general, the obtained results suggested that this method was unsuitable for the synthesis of $\mathbf{8}$ and $\mathbf{9}$.

To evaluate the relative stability of the isomeric five-, six-, and seven-membered formals, we calculated the free energies for their structures by DFT quantum-chemical B3LYP/6-31G (d,p) method, which was previously validated for solution of the similar task for stereoisomers of 


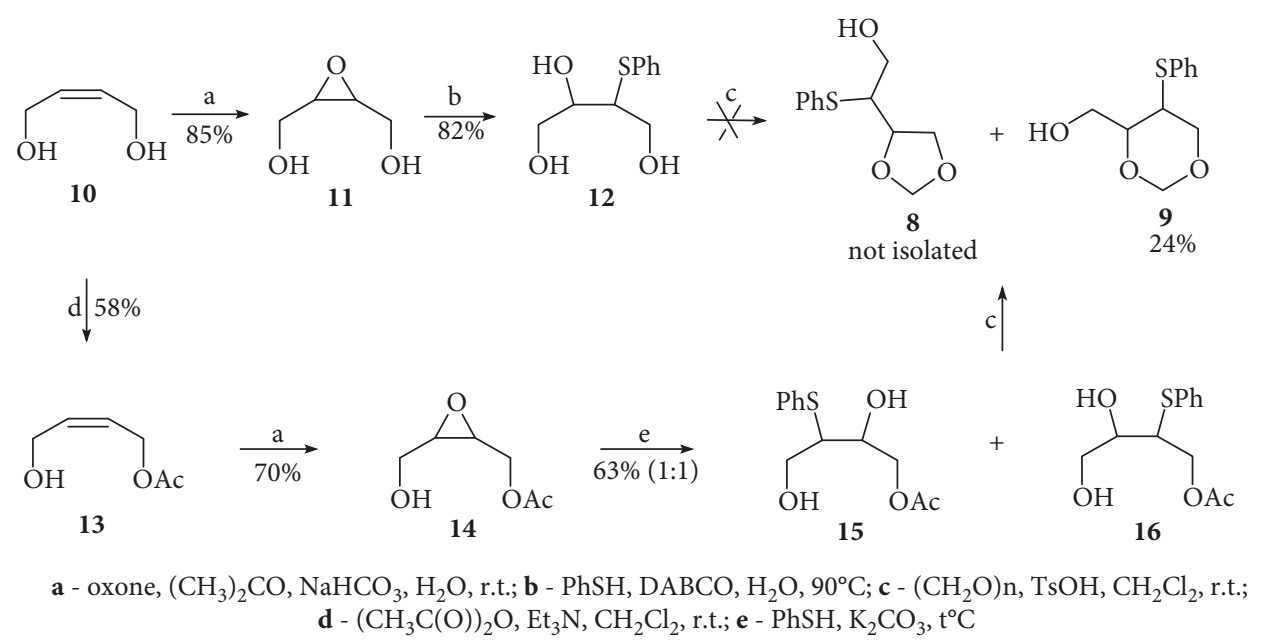

Scheme 2: Synthesis of hydroxysulfides of 1,3-dioxane and 1,3-dioxolane series.

oxirane 2 and related compounds [28, 29]. These calculations aimed at determination of relative thermodynamic stability of cyclic acetals of different types-dioxepanes, dioxanes, and dioxolanes. It was found that dioxolane $\mathbf{8}$ and dioxane 9 were less stable than dioxepane 3 . The differences in the relative values of free energies for the mentioned rings $\left(\Delta \triangle G_{298}\right.$ for the most stable conformers: $0.00 \mathrm{kcal} / \mathrm{mol}-$ dioxepan, $0.12 \mathrm{kcal} / \mathrm{mol}$-dioxolane, and $0.69 \mathrm{kcal} / \mathrm{mol}-$ dioxane) allowed us to evaluate the expected "thermodynamic" ratio of products in the gas phase as 56:38:6. Accounting of solvation effects and possible involvement of other conformers of each cyclic isomer, as well as calculations using a different basis, could slightly change this ratio, but the same trend was observed. Thus, the replacement of proton on thiophenyl group in the third position of butane1,2,4-triol led to preferential formation of the sevenmembered cyclic product in the reaction of condensation of this triol with paraformaldehyde. It can be concluded that formation of the seven-membered ring is advantageous both in terms of thermodynamic (calculated data) and kinetic (experimental data for the condensation reaction) control.

Compound 9 was obtained using a series of reactions depicted in Scheme 2. At the first step, reaction of diol $\mathbf{1 0}$ with acetic anhydride ( 0.8 mol. equiv.) resulted in monoacetylated derivative 13. According to ${ }^{1} \mathrm{H}$ NMR spectral data, the ratio of mono- and diacetylated products in unseparated mixture was $3: 1$. The analytical data for the obtained monoacetate 13 completely corresponded to those described in literature [19]. Compound $\mathbf{1 3}$ was then oxidized by oxone to previously described epoxide 14 [20]. Treatment of compound 14 with thiophenol in the presence of $\mathrm{K}_{2} \mathrm{CO}_{3}$ led to a mixture of regioisomers $\mathbf{1 5}$ and $\mathbf{1 6}$. The reaction was strongly exothermic, with the temperature increase up to $150^{\circ} \mathrm{C}$ that could explain the lack of the reaction selectivity. The resulting mixture of acetates $\mathbf{1 5}$ and $\mathbf{1 6}$ was purified from initial thiophenol and triol 12, formed in small amounts, by column chromatography on silica gel. The resulting acetates $\mathbf{1 5}$ and $\mathbf{1 6}$, which could not be separated, were treated with paraformaldehyde to obtain the corresponding mixture of compounds 8 and $\mathbf{9}$. Dioxane $\mathbf{9}$ was isolated by column chromatography on silica gel in $24 \%$ yield as white crystals. Its structure was confirmed by X-ray analysis (Figure 1). Dioxolane 8 could not be isolated in an individual form due to presence of impurities with close chromatographic mobility.

Our further synthetic effort was focused on structural modifications of compound $\mathbf{3}$, including their enantiomerically enriched forms (Scheme 3). Treatment of alcohol 3 with para-toluenesulfonyl chloride or methanesulfonyl chloride in the presence of triethylamine (path a) resulted in formation of chloride $\mathbf{1 7}$ in $87 \%$ and $76 \%$ yields, respectively. The reaction with thionyl chloride (path $b$ ) was less successful and led to the desired product in 52\% yield. Methyl ester 18 was prepared by reaction of chloride $\mathbf{1 7}$ in boiling methanol in the presence of an excess of sodium hydroxide.

The treatment of epoxide $\mathbf{2}$ with thiourea under aqueous acidic conditions led to episulfide 19. The latter was treated with thiophenol in the presence of potassium carbonate without a solvent to obtain mercaptan 20 [28]. In addition, reactions of epoxide 2 with various nucleophiles, including benzylthiol, phenol, aniline, and halogen-substituted thiophenols, resulted in a series of congeneric alcohols 21-33.

Structures of all the synthesized compounds were confirmed by $1 \mathrm{D}$ and 2D NMR spectroscopy, mass spectroscopy, and X-ray analysis. X-ray structures of compounds $\mathbf{6}$, 7, and $\mathbf{9}$ are shown in Figure 1.

At the next stage, several racemic compounds were separated into enantiomers using enzymatic acylation by lipase PS (Scheme 4) [18]. As a result of two-step synthesis, we obtained optically active alcohols 3, 29, 31, 32, and 33, which had equal but opposite values of the rotation angles. Configuration of the chiral carbon atom at the hydroxyl group was assigned using the stereospecificity profile of reactions in the presence of lipase PS, in which only hydroxyl groups with R-configuration at the chiral center were prone to acylation. It was observed that the enzymatic reaction rate and optical purity of the resulting products did not depend on the nature and position of the halogen substituent in the aromatic rings of the studied thiophenyl moieties. 

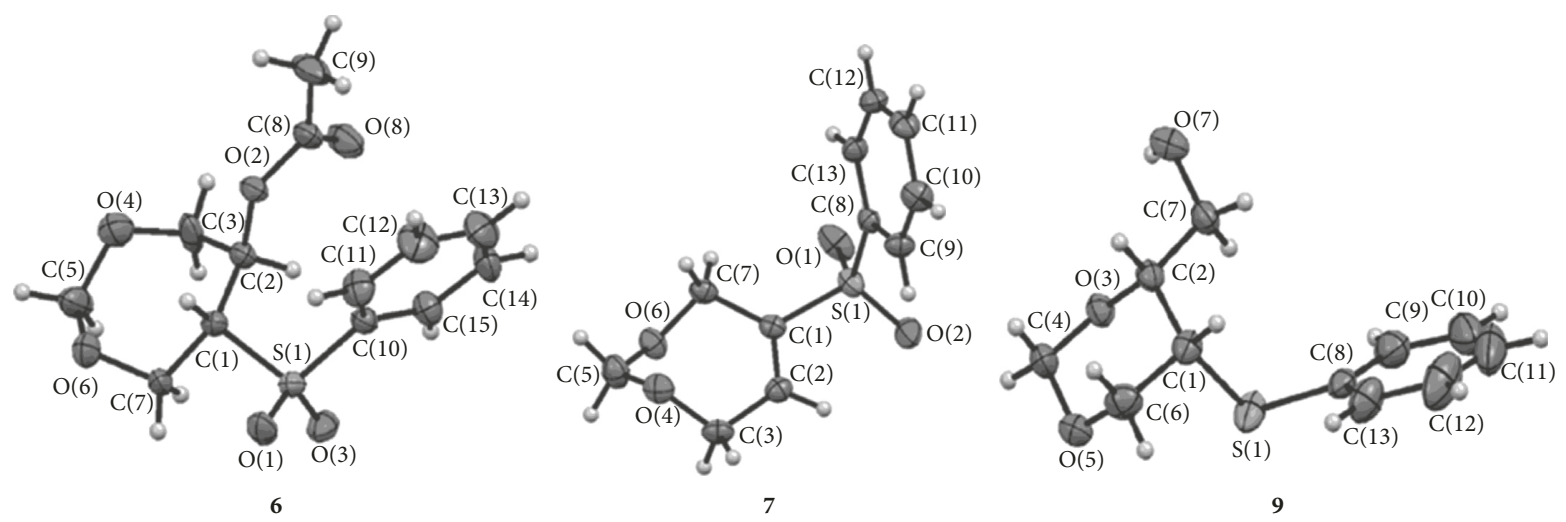

Figure 1: The geometry of compounds 6, 7, and $\mathbf{9}$ according to X-ray structural analysis.<smiles>OC1COCOCC1S</smiles>
$\stackrel{\text { a or b }}{87 \%(\mathrm{TsCl})}$
$76 \%(\mathrm{MsCl})$ $52 \%\left(\mathrm{SOCl}_{2}\right)$<smiles>SC1COCOCC1Cl</smiles><smiles>COC1COCOCC1[18SH]</smiles>
18

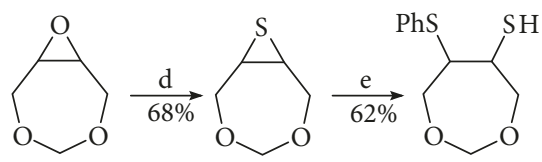

2 19 20<smiles>[13CH3][13CH3]</smiles><smiles>N#[N+]C1COCOCC1O</smiles>

$21-33$

$$
\begin{aligned}
& \text { a - } \mathrm{TsCl} \text { or } \mathrm{MsCl}, \mathrm{CH}_{2} \mathrm{Cl}_{2}, \mathrm{Et}_{3} \mathrm{~N} \text {, r.t.; } \\
& \text { b - } \mathrm{SOCl}_{2}, \mathrm{CH}_{2} \mathrm{Cl}_{2}, \mathrm{Et}_{3} \mathrm{~N} \text {, r.t.; } \\
& \text { c- } \mathrm{CH}_{3} \mathrm{OH}, \mathrm{NaOH} \text { reflux; } \\
& \text { d - }\left(\mathrm{NH}_{2}\right)_{2} \mathrm{CS}, \mathrm{H}_{2} \mathrm{O}, \mathrm{H}_{2} \mathrm{SO}_{4}, \mathrm{~K}_{2} \mathrm{CO}_{3} \text {, r.t.; } \\
& \text { e - } \mathrm{NuH}, \mathrm{K}_{2} \mathrm{CO}_{3}, 70^{\circ} \mathrm{C}
\end{aligned}
$$

NuH: BnSH (21), $\mathrm{PhOH}$ (22), $\mathrm{PhNH}_{2}$ (23), 2- $\mathrm{CH}_{3} \mathrm{PhSH}(\mathbf{2 4})$, 4- $\mathrm{CH}_{3} \mathrm{PhSH}$ (25), 2-ClPhSH (26), 4-ClPhSH (27) 2,4-Cl ${ }_{2} \mathrm{PhSH}$ (28), 2-FPhSH (29), 4-FPhSH (30), 2-BrPhSH (31), 3-BrPhSH (32), 4-BrPhSH (33)

Scheme 3: Synthesis of new functional derivatives of 1,3-dioxepane series.

To confirm the enantiomeric purity of the obtained alcohols, NMR spectra were obtained in the presence of a shift reagent, europium(III) tris[3-(heptafluoropropylhydroxymethylene)-(+)-camphorate. Figure 2 shows fragments of ${ }^{1} \mathrm{H}$ NMR spectra of the studied samples in the region of signals of hydrogen atoms at the acetal carbon atom. For the optically active alcohols, there are no signals of the second enantiomer, and these data suggest that the enantiomeric excess is close to $100 \%$. It should also be noted that a mismatch in the chemical shifts of the signals for each enantiomer with respect to racemate is explained by different amounts of the sample compounds loaded into a vial and the shift reagent. This factor also affects the shape and intensity of signals. The high enantiomeric purity (ee $>99 \%$ ) of the leading compound 32-SS was also confirmed by HPLC analysis on a chiral stationary phase.

At the final stage of the work, the antimycotic activity of the synthesized compounds against a panel of pathogenic microscopic fungi was tested. Specifically, we used four aggressive clinical isolates of fungi belonging to C. albicans, A. fumigatus, E. floccosum, and $M$. pusillus species. The in vitro experiment was carried out in liquid medium (Sabouraud glucose broth) using 2-fold serial dilutions in biological test tubes. Assessment of the culture growth was performed visually by comparing the growth of microorganisms in the presence of the studied test compounds and without them. The first lowest concentration of the tested sample (from a series of serial dilutions), where fungi growth was not visually detected, was considered as the minimum inhibitory concentration (MIC). As the reference compounds, two antimycotics with a broad spectrum of activity frequently used in clinical practice, fluconazole and terbinafine, were used.

The data presented in Table 2 indicate that several compounds had an expressed antifungal activity with MICs in the range of $15-60 \mu \mathrm{g} / \mathrm{ml}$. Thus, the leading compound 32 in the form of a dextrorotatory SS-enantiomer inhibited the growth of the studied fungi at the level of terbinafine, one of the most powerful systemic antimycotics. Fluconazole was significantly less active in this experimental series. To assess potential therapeutic window, we have measured the cytotoxic activity of the obtained compounds against the normal cells, human adipose tissue fibroblasts. The presented experimental data (Table 2) indicate that the leading compound 32-SS possesses a remarkable selectivity of action against the studied fungal pathogens (selectivity index is 5-10) as compared to terbinafine (selectivity index is $0.6-2$ against the studied pathogens).

\section{Conclusions}

In conclusion, in this work, we have developed efficient synthetic approaches to a series of novel 6-(arylthio)-1,3dioxepan-5-ols starting from 1,3-dioxacyclohept-5-ene through its oxidation followed by thiolysis with various thiophenols. Depending on the reaction conditions, this process can theoretically lead to the corresponding isomeric 

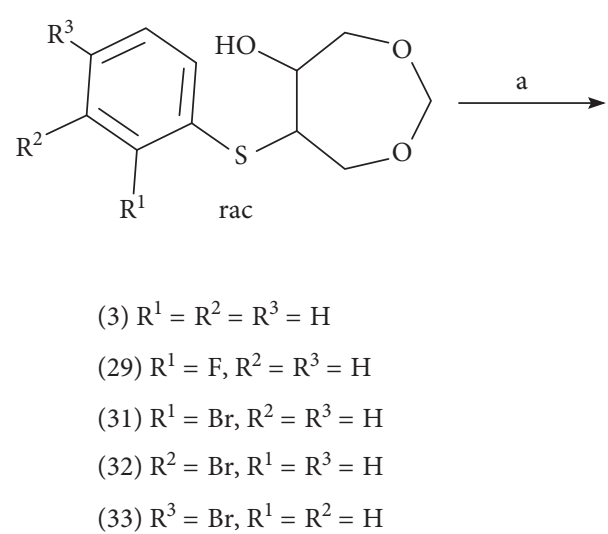<smiles>[R]c1ccc(S[C@@H]2COCOC[C@H]2O)c([R])c1[R]</smiles><smiles>[R]c1ccc(S[C@H]2COCOC[C@@H]2OC(C)=O)c([R])c1[R]</smiles>
(3) $\mathrm{R}^{1}=\mathrm{R}^{2}=\mathrm{R}^{3}=\mathrm{H}$
(29) $\mathrm{R}^{1}=\mathrm{F}, \mathrm{R}^{2}=\mathrm{R}^{3}=\mathrm{H}$
(31) $\mathrm{R}^{1}=\mathrm{Br}, \mathrm{R}^{2}=\mathrm{R}^{3}=\mathrm{H}$
(32) $\mathrm{R}^{2}=\mathrm{Br}, \mathrm{R}^{1}=\mathrm{R}^{3}=\mathrm{H}$
(33) $\mathrm{R}^{3}=\mathrm{Br}, \mathrm{R}^{1}=\mathrm{R}^{2}=\mathrm{H}$

(5) $\mathrm{R}^{1}=\mathrm{R}^{2}=\mathrm{R}^{3}=\mathrm{H}$

(34) $\mathrm{R}^{1}=\mathrm{F}, \mathrm{R}^{2}=\mathrm{R}^{3}=\mathrm{H}$

(35) $\mathrm{R}^{1}=\mathrm{Br}, \mathrm{R}^{2}=\mathrm{R}^{3}=\mathrm{H}$

(36) $\mathrm{R}^{2}=\mathrm{Br}, \mathrm{R}^{1}=\mathrm{R}^{3}=\mathrm{H}$

(37) $\mathrm{R}^{3}=\mathrm{Br}, \mathrm{R}^{1}=\mathrm{R}^{2}=\mathrm{H}$<smiles>[R]c1ccc(S[C@H]2COCOC[C@H](OC(C)=O)[C@@H]2[R])c([R])c1[R]</smiles><smiles>[R]c1ccc(S[C@@H]2COCOC[C@H]2O)c([R])c1[R]</smiles>
(5) $\mathrm{R}^{1}=\mathrm{R}^{2}=\mathrm{R}^{3}=\mathrm{H}$
(3) $\mathrm{R}^{1}=\mathrm{R}^{2}=\mathrm{R}^{3}=\mathrm{H}$
(34) $\mathrm{R}^{1}=\mathrm{F}, \mathrm{R}^{2}=\mathrm{R}^{3}=\mathrm{H}$
(29) $\mathrm{R}^{1}=\mathrm{F}, \mathrm{R}^{2}=\mathrm{R}^{3}=\mathrm{H}$
(35) $\mathrm{R}^{1}=\mathrm{Br}, \mathrm{R}^{2}=\mathrm{R}^{3}=\mathrm{H}$
(31) $\mathrm{R}^{1}=\mathrm{Br}, \mathrm{R}^{2}=\mathrm{R}^{3}=\mathrm{H}$
(36) $\mathrm{R}^{2}=\mathrm{Br}, \mathrm{R}^{1}=\mathrm{R}^{3}=\mathrm{H}$
(32) $\mathrm{R}^{2}=\mathrm{Br}, \mathrm{R}^{1}=\mathrm{R}^{3}=\mathrm{H}$
(37) $\mathrm{R}^{3}=\mathrm{Br}, \mathrm{R}^{1}=\mathrm{R}^{2}=\mathrm{H}$
(33) $\mathrm{R}^{3}=\mathrm{Br}, \mathrm{R}^{1}=\mathrm{R}^{2}=\mathrm{H}$

a - Lypase $\mathrm{PS}, 30-40^{\circ} \mathrm{C}, \mathrm{PhCH}_{3}$, vinylacetate; $\mathbf{b}-\mathrm{MeOH}, \mathrm{K}_{2} \mathrm{CO}_{3}$, r.t.

Scheme 4: Separation of racemic hydroxysulfides into enantiomers.
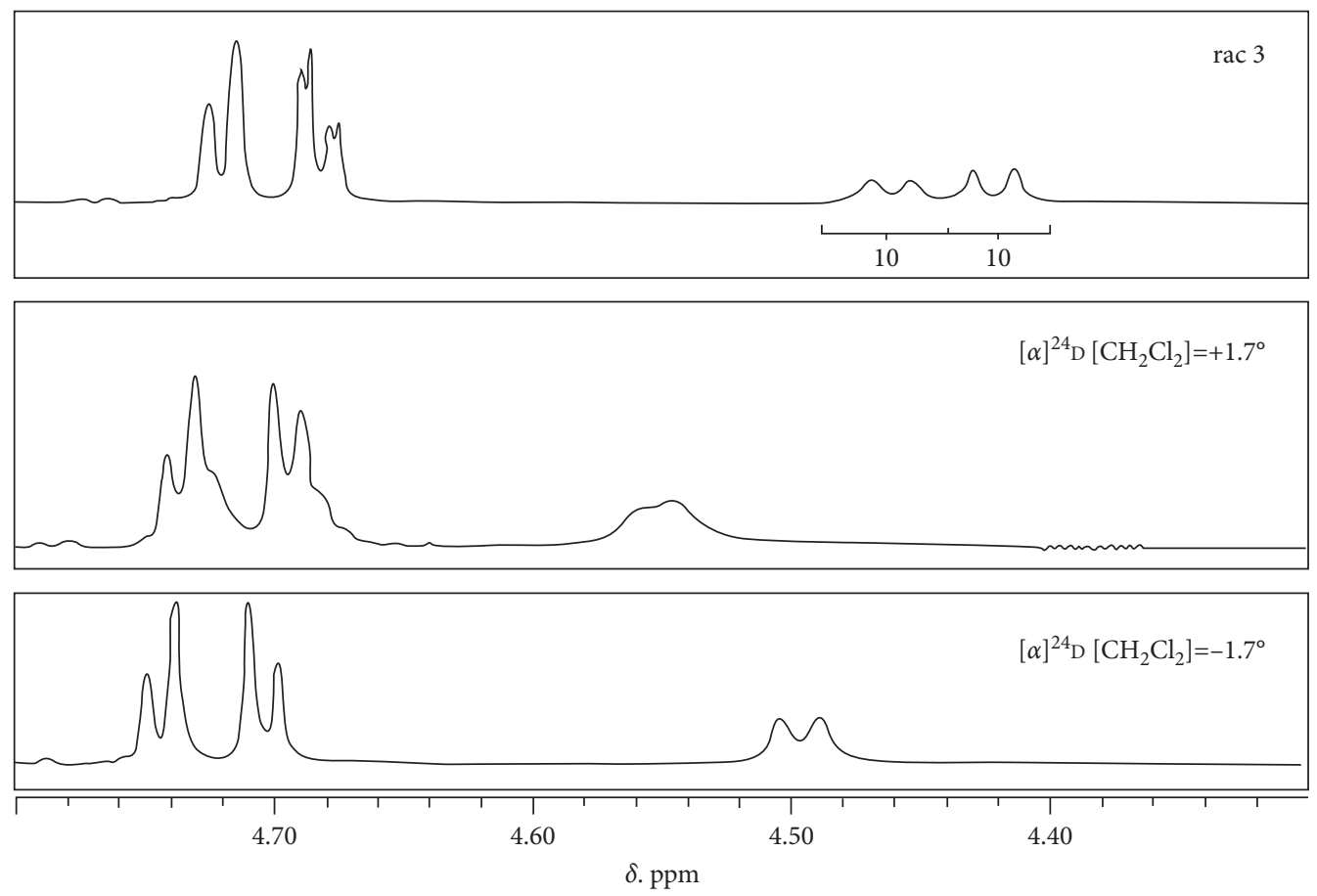

FIgURE 2: Fragments of $1 \mathrm{H}$ NMR spectra of racemic alcohol 3 and its enantiomers in the presence of a shift reagent. 
TABLE 2: Minimum inhibitory concentrations $(\mu \mathrm{g} / \mathrm{ml})$ of the synthesized compounds against the studied fungal strains.

\begin{tabular}{|c|c|c|c|c|c|}
\hline Compound & $\begin{array}{l}\text { Candida } \\
\text { albicans }\end{array}$ & $\begin{array}{l}\text { Aspergillus } \\
\text { fumigatus }\end{array}$ & $\begin{array}{l}\text { Epidermophyton } \\
\text { floccosum }\end{array}$ & $\begin{array}{l}\text { Mucor } \\
\text { pusilos }\end{array}$ & $\begin{array}{c}\mathrm{IC}_{50}(\mu \mathrm{g} / \mathrm{ml}), \text { human adipose tissue } \\
\text { fibroblasts }\end{array}$ \\
\hline 3-SS & 120 & 250 & 250 & 120 & $171.6 \pm 5.8$ \\
\hline 3-RR & 250 & 500 & 500 & 250 & $81.9 \pm 2.2$ \\
\hline 3 & 250 & 500 & 500 & 250 & $\mathrm{n} / \mathrm{a}$ \\
\hline 21 & $>500$ & $>500$ & $>500$ & $>500$ & $\mathrm{n} / \mathrm{a}$ \\
\hline 22 & 60 & 120 & $>500$ & 120 & $92.2 \pm 8.7$ \\
\hline 23 & $>500$ & $>500$ & $>500$ & $>500$ & $\mathrm{n} / \mathrm{a}$ \\
\hline 24 & 120 & 120 & 120 & 120 & $202.2 \pm 10.1$ \\
\hline 25 & 120 & 120 & 120 & 120 & $248.8 \pm 12.5$ \\
\hline 26 & 120 & 120 & 500 & 250 & $142.2 \pm 12.9$ \\
\hline 27 & 500 & 500 & $>500$ & 250 & $135.5 \pm 16.4$ \\
\hline 28 & $>500$ & $>500$ & $>500$ & $>500$ & $\mathrm{n} / \mathrm{a}$ \\
\hline 30 & $>500$ & $>500$ & $>500$ & $>500$ & $\mathrm{n} / \mathrm{a}$ \\
\hline 29-SS & 120 & 120 & 120 & 120 & $364.5 \pm 23.6$ \\
\hline 29-RR & 250 & 250 & 250 & 250 & $500.6 \pm 16.1$ \\
\hline 29 & 250 & 250 & 250 & 250 & $390.1 \pm 20.1$ \\
\hline $31-S S$ & 60 & 60 & 120 & 120 & $166.6 \pm 12.8$ \\
\hline 31-RR & 60 & 120 & 120 & 120 & $141.4 \pm 14.5$ \\
\hline 31 & 120 & 120 & 120 & 120 & $143.3 \pm 10.2$ \\
\hline 32-SS & 15 & 15 & 15 & 30 & $156.0 \pm 5.2$ \\
\hline 32-RR & 60 & 60 & 60 & 120 & $178.3 \pm 11.5$ \\
\hline 32 & 60 & 60 & 60 & 120 & $160.0 \pm 4.1$ \\
\hline 33-SS & 120 & 120 & 120 & 30 & $99.8 \pm 2.9$ \\
\hline 33-RR & 120 & 250 & 250 & 120 & $76.4 \pm 4.8$ \\
\hline 33 & 120 & 250 & 250 & 120 & $80.9 \pm 1.7$ \\
\hline Fluconazole & 120 & 250 & 250 & 250 & $>1500$ \\
\hline Terbinafine & 15 & 15 & 15 & 50 & $29.2 \pm 3.4$ \\
\hline
\end{tabular}

five-, six-, and seven-membered cyclic acetals: 1,3-dioxolanes, 1,3-dioxanes, and 1,3-dioxepanes, respectively. However, our experimental data supported by quantumchemical calculations using B3LYP/6-31G (d,p) method demonstrated that cyclic formals of 1,3-dioxepane series are the major products of this reaction. For such structures, the isomerization reaction is impossible due to instability of the intermediate carbocation. We have demonstrated that the corresponding 1,3-dioxolanes and 1,3-dioxanes can be obtained via alternative synthetic route based on condensation of monoacetylated butanetriols with paraformaldehyde.

Several racemic compounds of 1,3-dioxepane series have been separated into enantiomers using enzymatic acylation by lipase PS. For the optically active alcohols, our experimental data suggest that the developed approach leads to enantiomerically pure compounds with the enantiomeric excess close to $100 \%$.

Biological screening experiments have demonstrated that several compounds possess promising antifungal activity. Thus, the leading compound 32 with S-configuration of both stereocenters has expressed antifungal activity against four highly aggressive clinical isolates of fungi belonging to C. albicans, A. fumigatus, E. floccosum, and M. pusillus species, which is comparable with that of terbinafine and higher than activity of fluconazole. Of note, the synthesized 1,3-dioxanes were inactive against the studied fungal strains. The obtained chemotype represents a promising starting point for the development of viable antifungal drug candidates.

\section{Data Availability}

All the necessary analytical and other data are presented in the manuscript.

\section{Conflicts of Interest}

The authors declare that there are no conflicts of interest regarding the publication of this manuscript.

\section{Acknowledgments}

This paper is dedicated to Professor Evgenii Naumovich Klimovitskii, the scientist, who made a significant contribution to this direction of research, and the teacher, whose memory will remain forever in our hearts. This work was supported by Programs of Competitive Growth of Kazan (Volga region) Federal University and I.M. Sechenov First Moscow State Medical University.

\section{References}

[1] R. Zhang, S. Jin, Y. Wan, S. Lin, and Z. Yan, " $\mathrm{HBr} / \mathrm{H}_{2} \mathrm{O}_{2}$ mediated formation of C-S bond with thiosulfates," Tetrahedron Letters, vol. 59, no. 9, pp. 841-847, 2018.

[2] P. Tehri, B. Aegurula, and R. K. Peddinti, "Iodine-catalysed regioselective synthesis of $\beta$-hydroxysulfides," Tetrahedron Letters, vol. 58, no. 21, pp. 2062-2065, 2017.

[3] N. Azizi and M. Edrisi, "Biodegradable choline hydroxide promoted environmentally benign thiolysis of epoxides," Tetrahedron Letters, vol. 57, no. 5, pp. 525-528, 2016. 
[4] M.-Y. Chang, Y.-H. Huang, and H.-S. Wang, "Synthesis of 1,1-diarylethylenes," Tetrahedron, vol. 72, no. 22, pp. 30223031, 2016.

[5] S. R. Lanke, and B. M. Bhanage, "Amberlyst- $15^{\oplus}$ : an efficient heterogeneous reusable catalyst for selective anti-Markovnikov addition of thiols to alkenes/alkynes and for thiolysis of epoxides," Catalysis Communications, vol. 41, pp. 29-33, 2013.

[6] T. Sato, Y. Okumura, J. Itai, and T. Fujisawa, "(S)$\beta, \omega$-dihydroxyalkyl phenyl sulfones. Synthesis by bakers' yeast reduction and use as precursors of optically active lactones," Chemistry Letters, vol. 17, no. 9, pp. 1537-1540, 1988.

[7] R. Tanikaga, K. Hosoya, and A. Kaji, "Synthesis of enantiomerically pure 2,5-disubstituted tetrahydrofurans using readily prepared (2S)-1-phenylsulphonylalkan-2-ols," Journal of the Chemical Society, Perkin Transactions, vol. 1, pp. 1799$1803,1987$.

[8] J. Otera, H. Misawa, and K. Sugimoto, "Mechanistic aspects and profiles of the double elimination reaction of $\beta$-substituted sulfones," Journal of Organic Chemistry, vol. 51, no. 20, pp. 3830-3833, 1986.

[9] A. El-Awa, M. N. Noshi, X. M. Du Jourdin, and P. L. Fuchs, "Evolving organic synthesis fostered by the pluripotent phenylsulfone moiety," Chemical Reviews, vol. 109, no. 6, pp. 2315-2349, 2009.

[10] M. Dumic, D. Filic, M. Vinkovic, and B. Jamnicky, "Sulfonamidodioxepanes with hypoglycemic activity, methods of preparation, intermediates and salts thereof," EP 0668274, 1995.

[11] M. Dumic, D. Filic, M. Vinkovic, B. Jamnicky, and M. Eskinja, "N-Sulfonyl-tetrahydro-[1,3]-dioxepino[5,6]azirines with hypoglycemic activity," EP 0669335, 1995.

[12] A. K. Ghosh, S. Gemma, A. Baldridge et al., "Flexible cyclic ethers/polyethers as novel P2-ligands for HIV-1 protease inhibitors: design, synthesis, biological evaluation, and proteinligand X-ray studies," Journal of Medicinal Chemistry, vol. 51, no. 19, pp. 6021-6033, 2008.

[13] R. S. Pavelyev, S. G. Gnevashev, R. M. Vafina et al., "Synthesis and antimycotic properties of hydroxy sulfides derived from exo- and endo-4-phenyl-3,5,8-trioxabicyclo[5.1.0]octanes," Mendeleev Communications, vol. 22, no. 3, pp. 127-128, 2012.

[14] M. J. Frisch, G. W. Trucks, H. B. Schlegel et al., Gaussian 98, Revision A.7, Gaussian, Inc., Pittsburgh, PA, USA, 1998.

[15] A. P. Scott and L. Radom, "Harmonic vibrational frequencies: an evaluation of Hartree-Fock, Møller-Plesset, quadratic configuration interaction, density functional theory, and semiempirical scale factors," Journal of Physical Chemistry, vol. 100, no. 41, pp. 16502-16513, 1996.

[16] M. H. Gianni, R. Cody, M. R. Asthana, K. Wursthorn, P. Patanode, and H. G. Kuivila, "The role of the generalized anomeric effect in the conformational analysis of 1,3-dioxacycloalkanes. Conformational analysis of 3,5-dioxabicyclo [5.1.0]octanes and 3,5,8-trioxabicyclo[5.1.0]octanes," Journal of Organic Chemistry, vol. 42, no. 2, pp. 365-368, 1977.

[17] J. V. Schloss and F. C. Hartman, "Synthesis and characterization of cis- and trans-2,3-epoxybutane-1,4-diol 1,4-bisphosphate, potential affinity labels for enzymes that bind sugar bisphosphates," Bioorganic Chemistry, vol. 9, no. 2, pp. 217-226, 1980.

[18] O. Yamada and K. Ogasawara, "Lipase-mediated preparation of optically pure four-carbon di- and triols from a mesoprecursor," Synthesis, vol. 1995, no. 10, pp. 1291-1294, 1995.

[19] A. De La Cruz, A. He, A. Thanavaro, B. Yan, C. D. Spilling, and N. P. Rath, "Allylic hydroxy phosphonates: versatile chiral building blocks," Journal of Organometallic Chemistry, vol. 690, no. 10, pp. 2577-2592, 2005.

[20] J.-L. Brevet and K. Mori, "Pheromone synthesis; CXXXIX. Enzymatic preparation of (2S,3R)-4-acetoxy-2,3-epoxybutan1 -ol and its conversion to the epoxy pheromones of the gypsy moth and the ruby tiger moth," Synthesis, vol. 1992, no. 10, pp. 1007-1012, 1992.

[21] G. M. Sheldrick, "A short history of SHELX," Acta Crystallographica Section A: Foundations of Crystallography, vol. 64, no. 1, pp. 112-122, 2007.

[22] L. J. Farrugia, "WinGX suite for small-molecule single-crystal crystallography," Journal of Applied Crystallography, vol. 32, no. 4, pp. 837-838, 1999.

[23] APEX (Version 2.1), SAINTPlus. Data Reduction and Correction Program, Version 7.31A, Bruker Advanced X-Ray Solutions. BrukerXS Inc., Madison, WI, USA, 2006.

[24] L. Rittie, and G. J. Fisher, "Isolation and culture of skin fibroblasts," Methods in molecular medicine, vol. 117, pp. 83-98, 2005.

[25] J. Deutsch, A. Martin, and H. Lieske, "Investigations on heterogeneously catalysed condensations of glycerol to cyclic acetals," Journal of Catalysis, vol. 245 , no. 2, pp. 428-435, 2007.

[26] J.-L. Gras, R. Nouguier, and M. Mchich, "Transacetalisation de triols a partir du dimethoxymethane. Selectivite et applications synthetiques," Tetrahedron Letters, vol. 28, no. 52, pp. 6601-6604, 1987.

[27] P. A. MacNeil, N. K. Roberts, and B. Bosnich, "Asymmetric synthesis. Asymmetric catalytic hydrogenation using chiral chelating six-membered ring diphosphines," Journal of the American Chemical Society, vol. 103, no. 9, pp. 2273-2280, 1981.

[28] V. V. Gavrilov, A. B. Dobrynin, R. M. Vafina et al., "Synthesis and stereochemistry of 4-tert-butyl-4-oxo-3,5,8-trioxa (3,5dioxa-8-thia)-4-phosphabicyclo [5.1.0]octanes and related acetals," Journal of Molecular Structure, vol. 837, no. 1-3, pp. 79-85, 2007

[29] A. E. Klimovitskii, E. E. Zvereva, G. A. Chmutova et al., "Conformational isomerism in 3,5,8-trioxabicyclo [5.1.0]octane and its diastereomeric 4-methyl derivatives. A combined IR, X-ray and ab initio study," Journal of Molecular Structure, vol. 828, no. 1-3, pp. 147-153, 2007. 

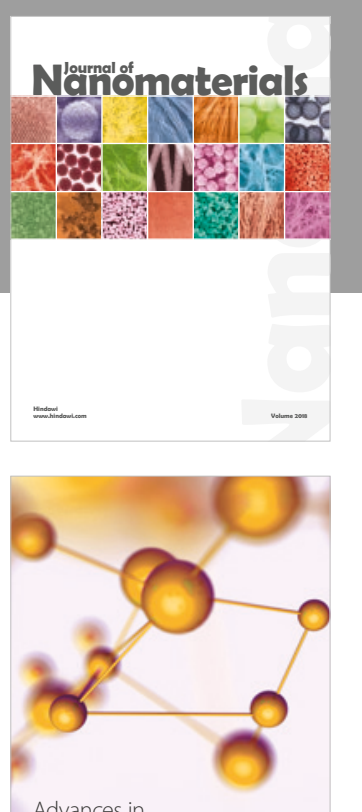

Physical Chemistry
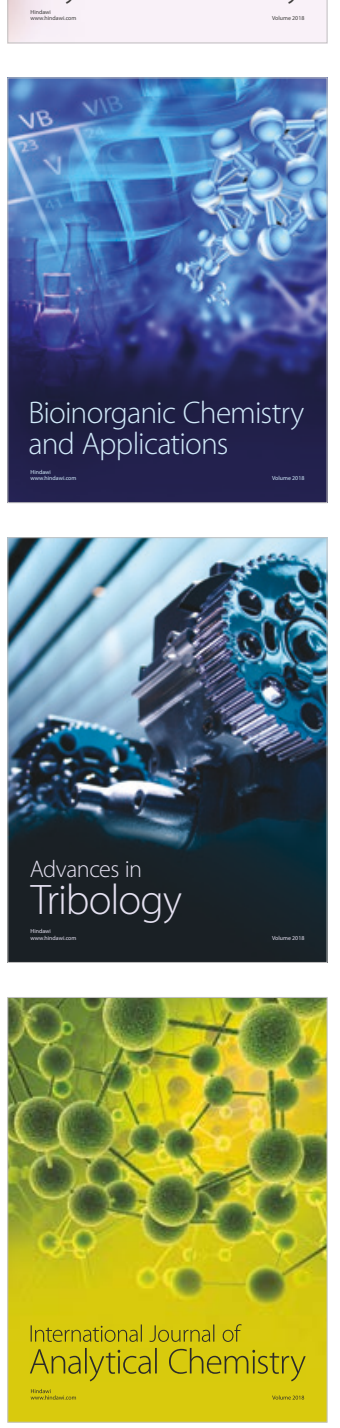

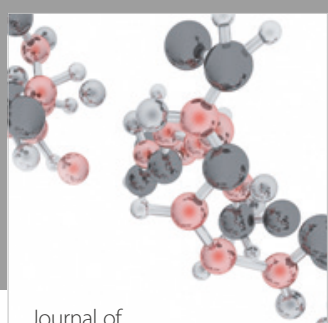

Analytical Methods

in Chemistry

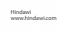

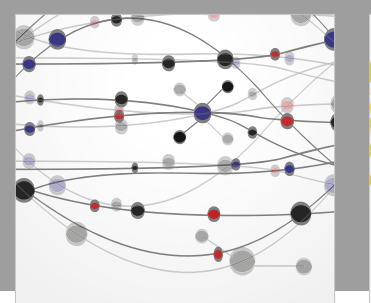

The Scientific World Journal

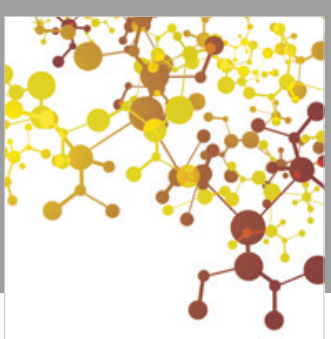

Journal of

Applied Chemistry
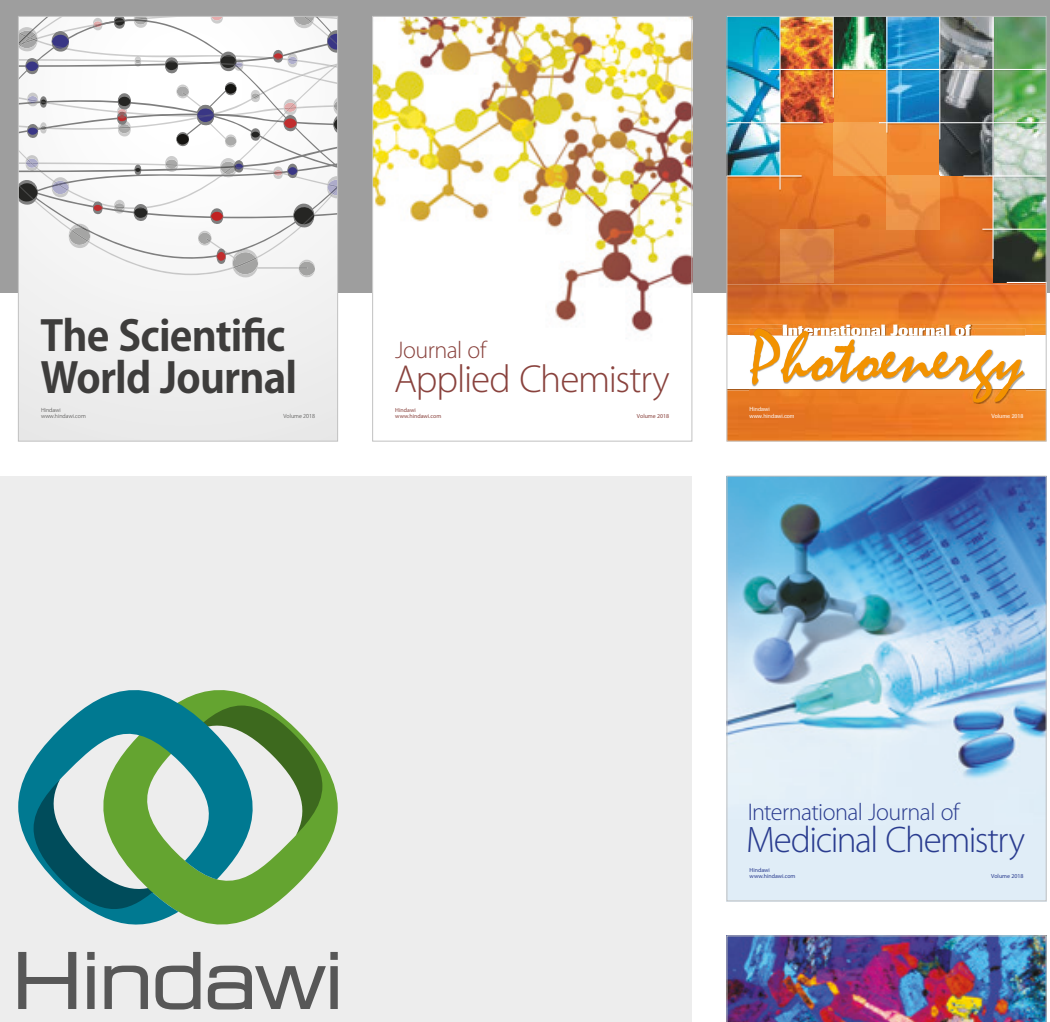

Submit your manuscripts at

www.hindawi.com
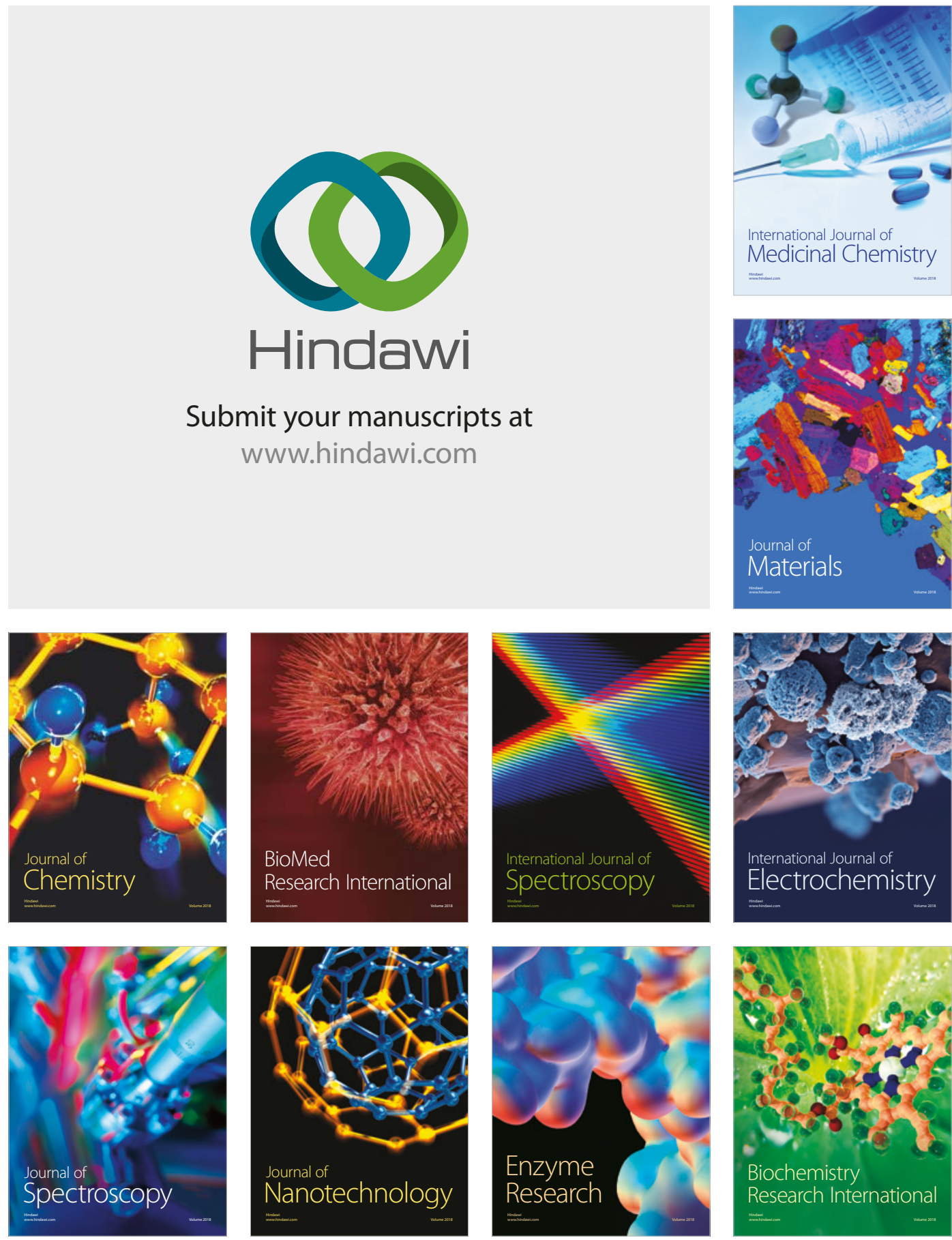
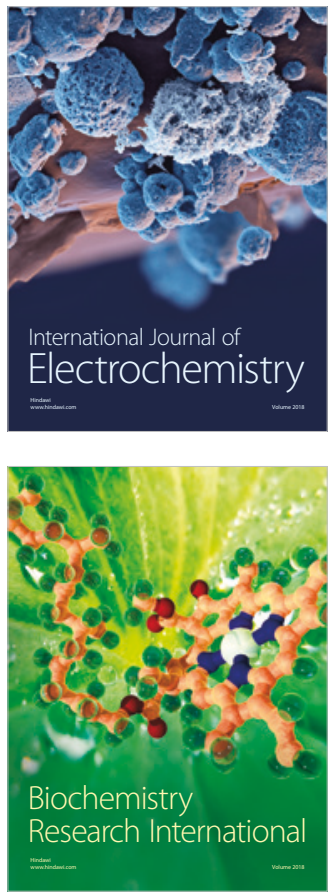